\title{
Improved permeability prediction based on the feature engineering of petrophysics and fuzzy logic analysis in low porosity-permeability reservoir
}

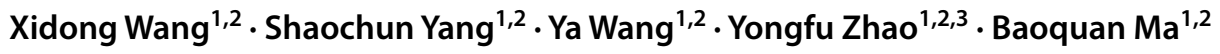

Received: 27 January 2018 / Accepted: 5 October 2018 / Published online: 13 October 2018

(c) The Author(s) 2018

\begin{abstract}
Permeability is difficult to evaluate in reservoir petrophysics property, especially in low porosity-permeability reservoir. The conventional permeability estimation model with establishment of the regression relationship between permeability and porosity is not applicable. This regression hypothesis based on the correlation between porosity and permeability (logarithm) is not available in low porosity-permeability reservoir. It remains a challenging problem in tight and heterogeneous formations' petrophysical interpretation. Feature engineering process, as the most significant procedure in data-driven analytics, indicates that accurate modelling should be based on the main control factor on permeability ignoring its concrete mathematical expression. To select the factors that influence the main function of the model, and use the appropriate model to carry out the model structure, fusion and optimization is the main task to permeability estimation in low porosity-permeability reservoirs. Fuzzy logic, as a widely used approach in estimation of permeability, can be used to estimate the permeability with the advantage of tolerance. Its good adaptation in objective contradictory concepts and false elements in computational processes outweighs the traditional method on permeability estimation which always lies in a wide distribution of orders of magnitude. The research takes the permeability estimation issue in Mesozoic strata, Gaoqing area as example. The area of study mainly contains reservoirs with low-to-ultra-low porosity-permeability. The relationship between porosity and permeability is somewhat certain but insufficient using the regression method to predict. The research combined specialized feature engineering process with the fuzzy logic analysis to predict permeability. First, this paper analyzes that the main control factors of permeability in the region is the homogenization by diagenetic with statistical multivariate variance analysis SNK (Student-Newman-Keuls) method. It can be characterized by $\Delta \varphi$, the changing degrees of porosity. To characterize the permeability response in well logs, the variables standing for a comprehensive reflection of the formation hydrology, lithology, and diagenesis are selected in the result of the electrofacies, SP, LLS, AC by multivariate variable selection method. The study is trying to combine the logging principle to explain its physical meaning by the statistical results. For discrete variables like electrofacies in modelling, scale quantization should be conducted by the optimal scale analysis considering discrete variables influences on permeability instead of manual labelling by numbers. Finally, the fuzzy logic analysis is carried out to achieve the results. The study makes a comparison of results in three ways to indicate the importance of feature engineering. That is, improved results with optimized model, model without feature engineering, and ordinary regression model. The optimized model with feature engineering predicts the permeability more conformed to the core data.
\end{abstract}

Keywords Permeability estimation $\cdot$ Low porosity-permeability reservoir $\cdot$ Feature engineering $\cdot$ Fuzzy logic $\cdot$ Data-driven analytics

\section{Introduction}

Permeability prediction is one of the most important tasks in oil and gas reservoir evaluation. The core laboratory analy-

Xidong Wang

microdifficult@163.com

Extended author information available on the last page of the article sis obtained from drilling provides the most reliable permeability value. Because of the complexity of cost and process, this method cannot be popularized in large areas. The 
conventional permeability prediction is based on the regression analysis of multivariate statistics, and the most common approach is to establish a regression formula between porosity and permeability. However, the real laboratory core results confirmed that the core permeability and permeability prediction by regression has big errors especially in low porosity-permeability reservoir. It remains a challenge in tight and heterogeneous formations.

The prediction of permeability is developed with theory and techniques (Geerits et al. 1999; Anifowose et al. 2013a, b, 2014a, b, c; Hassan et al. 2013). The method in early times is to incorporate the variables associated with the permeability, such as porosity, saturation and capillary pressure, into the permeability regression model (Coates and Dumanoir 1974; Kozeny 1927; Carman 1937). It forms a series of models such as the famous Coats formula and the Kozeny-Carman formula; Lev Vernik (2000) set up an exponential model based on porosity and shale content control, but it is only applicable to shallow ocean sediments and fluvial deltaic sediments strongly correlated with the particle (pore) size of weakly diagenetic rocks; Faruk Civan (2002) incorporates the fractal attributes of connected pore space into a bundle of tortuous leaky hydraulic tubes model of porous media to estimate permeability. The logging technique is also improved. Nuclear magnetic resonance (NMR) logs are also used to obtain good estimates of pore-space characteristics to improve permeability correlations (Sen et al. 1990; Coates et al. 1991; Quintero et al. 1999; Amabeoku et al. 2001). Array Sonic Logging utilizes the properties of the frequency shift and time delay of the wave to indicate good permeability result (Winkler 1989). Baziar et al. (2014) employ co-active neuro-fuzzy inference system and support vector machine to predict permeability of Mesaverde tight gas sandstones located in Washakie Basin in USA. Permeability prediction in sandstone reservoirs using data mining and expert system approach is done in KS field (Nashawi and Malallah 2009; Gholami et al. 2012).

The low porosity-permeability reservoir has its own characteristics: the heterogeneity of the strata caused by different curvature and shape coefficients of the pore throat results in a drastic change in samples; a disproportionate correlation makes samples in same porosity probably with simultaneous presence of permeability in high- and low-displayed with high scattering in crossplot. Any empirical correlation obtained from such a plot is vulnerable to unrealistic results. All these limit the prediction accuracy and precision of the permeability in low porosity-permeability reservoir. Feature engineering is the key process of discovering features that have a significant impact on the target variable (Qian et al. 2016). In this study, feature engineering procedure in DataDriven Analytics is paid most attention to characterize the change in the representation of permeability. It is modeled from the main geological effects using advanced technology and a comprehensive process to analyze and select the main control factor that can be represented as variables, and use appropriate analytical means to carry out model construction, integration, and optimization. According to the characteristics of Mesozoic clastic strata in Gaoqing area, feature engineering process is conducted by a comprehensive analysis by reservoir physical analysis and statistical multivariate variance analysis SNK method. The optimal scale analysis is used to quantify the variable scale for the existence of discrete variables. Finally, it adopts the fuzzy logic algorithm which can tolerate and explain the objective contradictions. It allows the calculation process to be modeled with the error components. Compared with the traditional regression, fuzzy logic algorithm with feature engineering predicts the permeability more conformed to the core data.

\section{Area of study}

The Mesozoic buried hill in Gaoqing area is one of the ancient buried hill in Jiyang depression with its Mesozoic strata sloping towards the North. The stratum at the top of Mesozoic is invaded by multi-stage magma. Meanwhile, the formation is raised to the surface under the sharp lifting of the faulting in the south of study area. Long-term weathering and erosion caused hiatus between Mesozoic stratigraphy and overlying strata Kongdian formation constructing angular unconformity (Jiang 1998).

The Mesozoic strata are incomplete. The lithology near Mesozoic unconformity structure in Gaoqing area is red and purple, gray purple, gray mudstone with tuffaceous sandstone or conglomerate and multilayer mafic volcanic, such as gray-green rock, diorite rocks, and igneous rocks. The remaining strata are mainly distributed in the Northern Slope in Gaoqing field forming angular unconformity. Reservoir is mainly located in sandstone, siltstone, and basalt gravel buried shallow with the attribute of low porosity and low permeability.

\section{Methodology}

\section{Data scenario}

Core data utilized in the study is collected in Mesozoic stratigraphy and the formation of overlying unconformity structure in Gaoqing area: three coring wells (including porosity, permeability and density) with definition of rock and microscope observation of core slice, 21 wells with a complete series of well-logging data. Considering the unbalanced distribution of the sample counts, the sample set was divided into two subsets with equal counts, one for training 
and one for testing the ability of the trained classifier to correctly assign classes. Nomenclature is as follows:

\begin{tabular}{ll}
\hline Nomenclature & \\
\hline GR, gamma ray & DEN, the density logging \\
SP, spontaneous potential & AC, the acoustic time logging \\
LLD, the deep-lateral logging & Elec, electrofacies \\
LLS, the shallow-lateral logging & \\
\hline
\end{tabular}

\section{Reservoir properties}

A classification of the region's electrofacies is obtained using an optimized KNN clustering method (Wang et al. $2018 \mathrm{~b}, \mathrm{c}$ ) based on the characteristics of logging response of GR, SP, LLD, LLS, AC, and DEN. The optimized KNN clustering method based on weighed cosine distance was proposed to better fit the electrofacies Model. To deal the problem for the initial center selection and outliers, a set of statistic method like box plots is conducted. A better cluster series center to feature more information about electrofacies and new distance algorithm selection is obtained in the base of geology model and a logging data similarity attribute when utilizing $\mathrm{KNN}$ clustering. It is divided into six classes of electrofacies by this method (Table 1).
The overall distribution of porosity and permeability are shown in Figs. 1 and 2. The pore-permeability distribution has good morphological similarity, which indicates that it has slightly certain correspondence. According to the standard of clastic reservoir classification in Table 2, the porosity has obvious multiple humps distribution, and the main distribution locates in ultra-low porosity in a mean value of $5 \%$ and the low-to-middle porosity ranging from 10 to $20 \%$ with least extra-high porosity. The permeability distribution is mainly concentrated in ultra-low permeability and low-permeability reservoir ranging from $1 \times 10^{-3} \mu \mathrm{m}^{2}$ to $40 \times 10^{-3} \mu^{2}$. The permeability distribution has obvious double-humped properties. With $1 \times 10^{-3} \mu \mathrm{m}^{2}$ and $40 \times 10^{-3} \mu \mathrm{m}^{2}$ as the two humps characteristics, they all belong to the ultra-low-to-low permeable strata. In a whole, the region mainly distributes low porosity-low permeability and low porosity-ultra-low permeability reservoir and develops few middle porosity-low permeability reservoirs.

By analyzing the distribution of pore permeability by the classification of the electrofacies in Figs. 3 and 4, it can be seen that the porosity and permeability also has a correspondence. Elec1 and Elec2 show significant ultra-low porosity and ultra-low permeability features with a value range of $\varphi \leq 10 \%, \mathrm{~K} \leq 1 \times 10^{-3} \mu \mathrm{m}^{2}$. There is a high-permeability point in the distribution that remains to be observed. Porosity distribution in Elec3 has a large range with a slight

Table 1 The cluster center and the definition of the electrofacies

\begin{tabular}{lclcclll}
\hline Code & GR & SP & LLD & LLS & AC & DEN & Definition \\
\hline 1 & 83.14 & 113.65 & 7.45 & 6.71 & 211.89 & 2.46 & Mainly composed of pyroxene, plagioclase, dark gray blocky structure of intrusive rock \\
2 & 178.1 & 108.8 & 19.26 & 17.69 & 202.1 & 2.48 & Composed mainly of volcanic ash to form igneous rocks in the block structure \\
3 & 73.07 & 112.62 & 4.73 & 4.35 & 263.97 & 2.23 & Composed mainly of mafic glass with vesicular structure of volcano rock \\
4 & 147.91 & 108.27 & 12.9 & 12.1 & 228.63 & 2.45 & Mainly composed of quartz and feldspar sand structure, coarse grains \\
5 & 154.13 & 112.71 & 7.22 & 6.55 & 239.92 & 2.36 & $\begin{array}{c}\text { Mainly composed of quartz and feldspar sand fine sand structure, particle size smaller } \\
\text { with fine compaction and dissolution }\end{array}$ \\
6 & 152.54 & 113.51 & 6.97 & 5.905 & 254.1 & 2.24 & Dense fine-grained sandstone with fine cementation \\
\hline
\end{tabular}

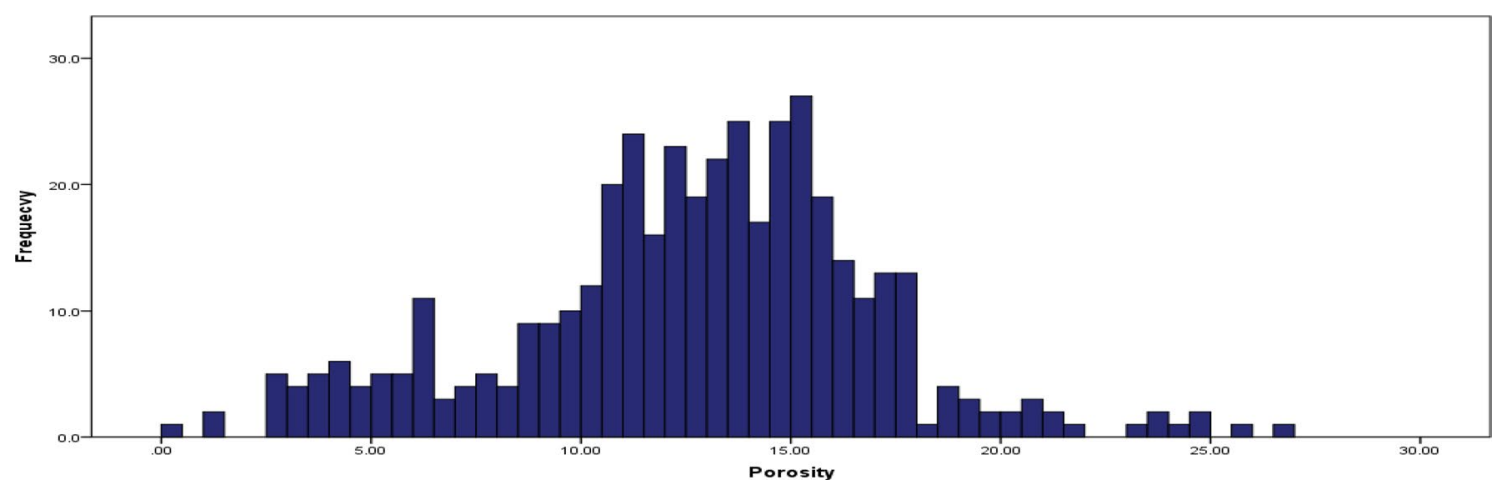

Fig. 1 Overall distribution of porosity (\%) 


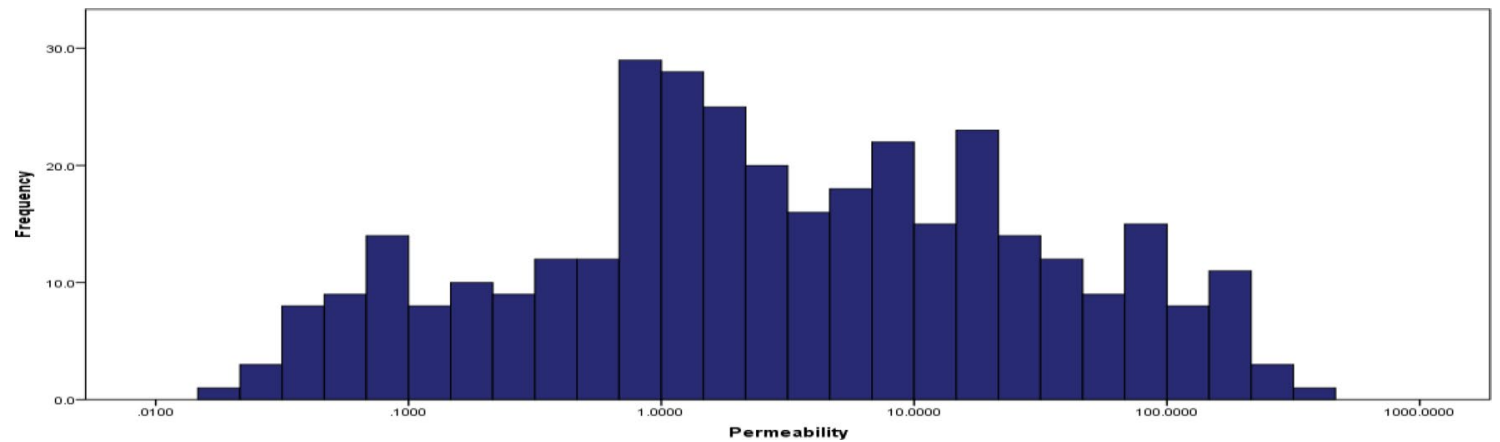

Fig. 2 Overall distribution of permeability $\left(1 \times 10^{-3} \mu \mathrm{m}^{2}\right)$

Table 2 Criterion for classification of Clastic reservoir physical property

\begin{tabular}{lll}
\hline Classification of reservoir by petrophysics & Porosity $\varphi(\%)$ & $\begin{array}{l}\text { Permeability K } \\
\left(1 \times 10^{-3} \mu \mathrm{m}^{2} \text { i.e., }\right. \\
\mathrm{mD})\end{array}$ \\
\hline Extra high porosity and high permeability & $\varphi \geq 30$ & $\mathrm{k} \geq 2000$ \\
High porosity and high permeability & $25 \leq \varphi<30$ & $500 \leq \mathrm{k}<2000$ \\
Middle porosity and middle permeability & $15 \leq \varphi<25$ & $50 \leq \mathrm{k}<500$ \\
Low porosity and low permeability & $10 \leq \varphi<15$ & $5 \leq \mathrm{k}<50$ \\
Ultra-low porosity and ultra-low permeability & $\varphi \leq 10$ & $\mathrm{k} \leq 5$ \\
\hline
\end{tabular}

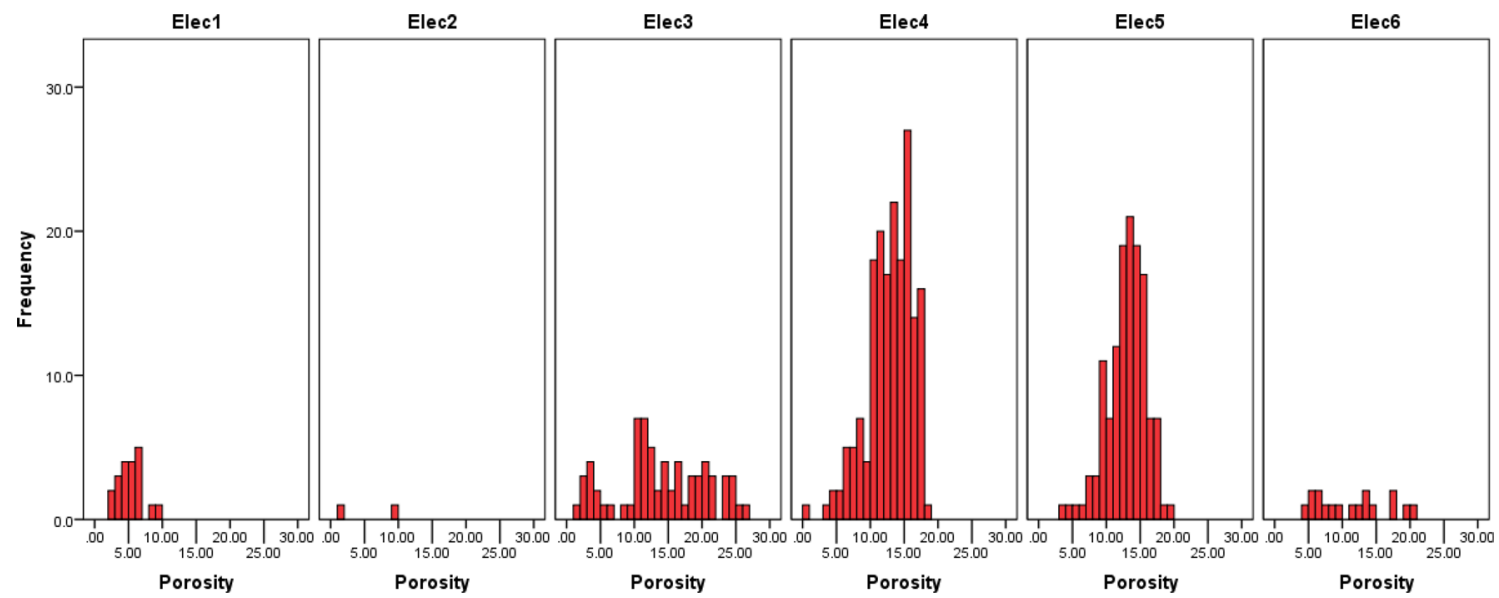

Fig. 3 Overall distribution of porosity in electrofacies categories

right tendency distribution, mainly displaying low pore distribution. At the same time there are fewer ultra-low porosity and more middle porosity, and the permeability distribution is mainly distributed in the low-permeability reservoir with a value of $1 \times 10^{-3} \mu \mathrm{m}^{2}$, but a small amount of middle per-

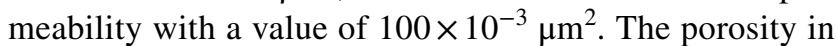
Elec4 and Elec5 has a similar left tendency single humped distribution, mainly in the middle and low pore, and the permeability distribution has a big difference: permeability distribution in Elec4 has obvious double-humped properties with the presence of the hump values of $1 \times 10^{-3} \mu \mathrm{m}^{2}$ and
$40 \times 10^{-3} \mu \mathrm{m}^{2}$ at the same time, while low permeability and middle permeability are also developed. A single hump is developed in Elec5 within the limit in $10 \times 10^{-3} \mu^{2}$ and a major distribution of the peak in $1 \times 10^{-3} \mu \mathrm{m}^{2}$, showing the characteristics of ultra-low permeability. Low permeability and middle permeability characteristics are undeveloped. Elec6 has a large range of distributions as same, mainly with low porosity and a small amount of middle porosity.

Box plot can indicate the information about symmetry of the data, distribution of the degree of dispersion, especially it can be used to analyze discrete outliers and the extremes. 
As is shown in Figs. 5 and 6, the permeability distribution in Elec1 has an extreme value. The porosity distribution in Elec4 appears as two outliers. There are also outliers in the distribution of pore permeability in Elec5. By contrastive analysis, extreme values and outliers values are divided into two types. Class 1: the great differences between a sample

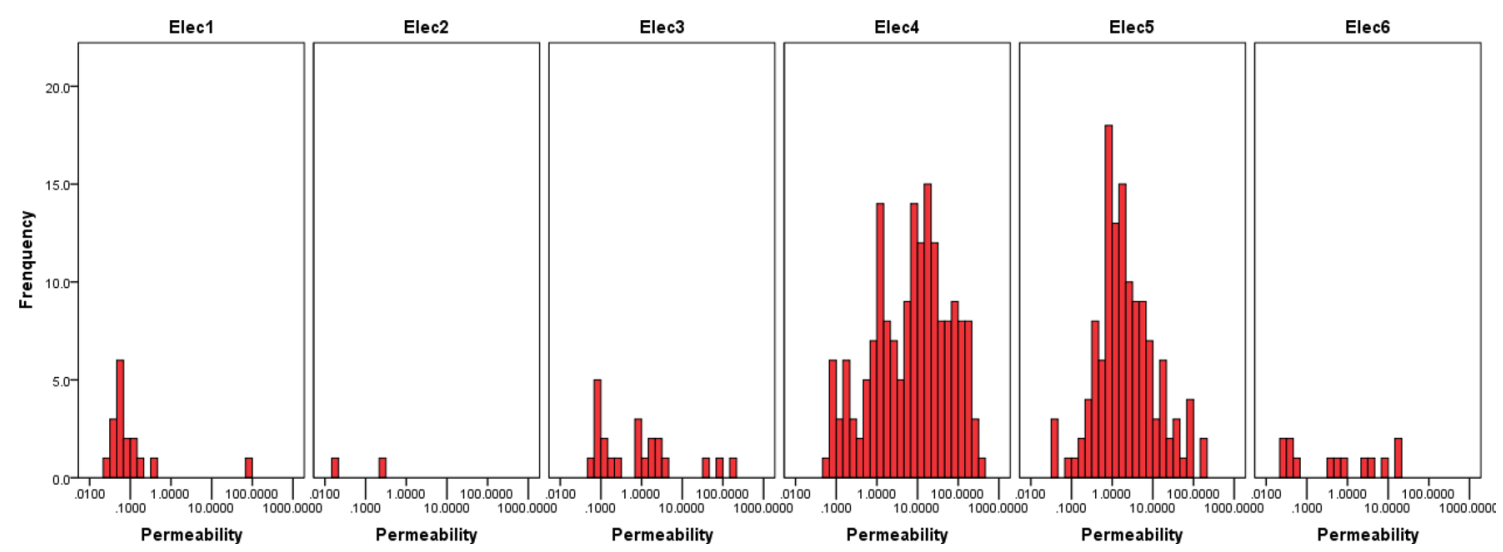

Fig. 4 Overall distribution of permeability in electrofacies categories

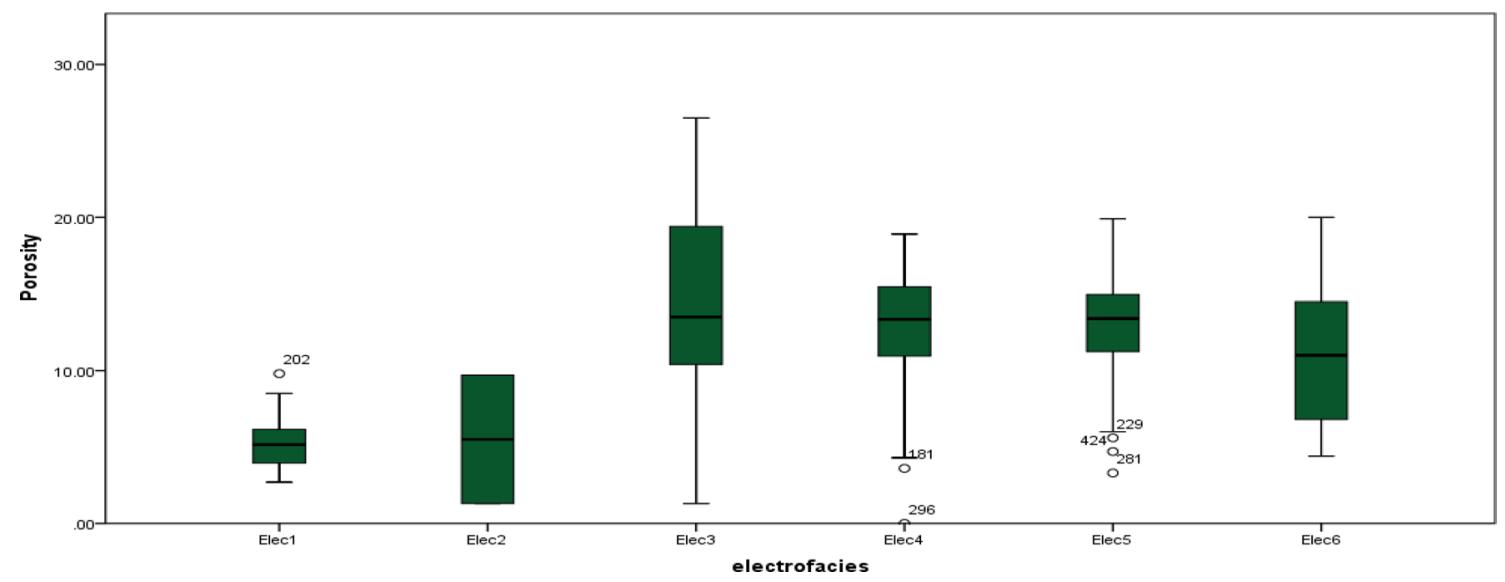

Fig. 5 Box plot of porosity in electrofacies

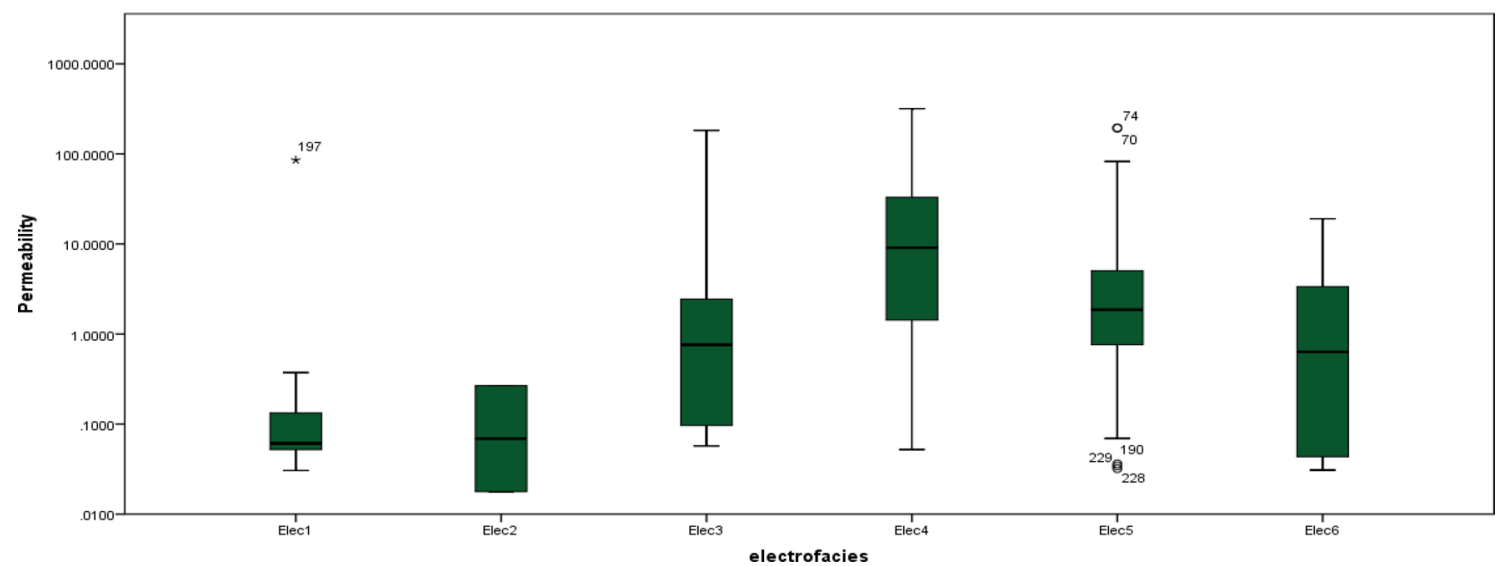

Fig. 6 Box plot of permeability in electrofacies 
and its adjacent sample have a great effect on petrophysics. Such as extreme point Sample 197 labeled by cross of Elec1, is close to the sample points of Elec4, Sample 198. Class 2: because of the quantitative classification of electrofacies, samples in transition zones of the electrofacies will also cause disperse phenomenon displayed as outliers in box plot like Sample 229, 424 labeled by circle. Therefore, for the precision of the permeability modeling, the study is carried out by eliminating outlier samples in Class 1 , standing still for the samples in Class 2.

\section{The main control factors of permeability}

Feature engineering is a typical work to determine the main effect factors and characterize the factor as a parameter in model (Qian et al. 2016). The first task is to figure out the main control factors of permeability. In general (Zeng and Li 2009), the petrophysics of the reservoir is controlled by the particle size, sorting, and diagenesis if no significant development of fracture is involved in the characteristics. (Abbaszadeh et al. 1996). The main factors that affect the petrophysics of oil reservoirs can be inferred by

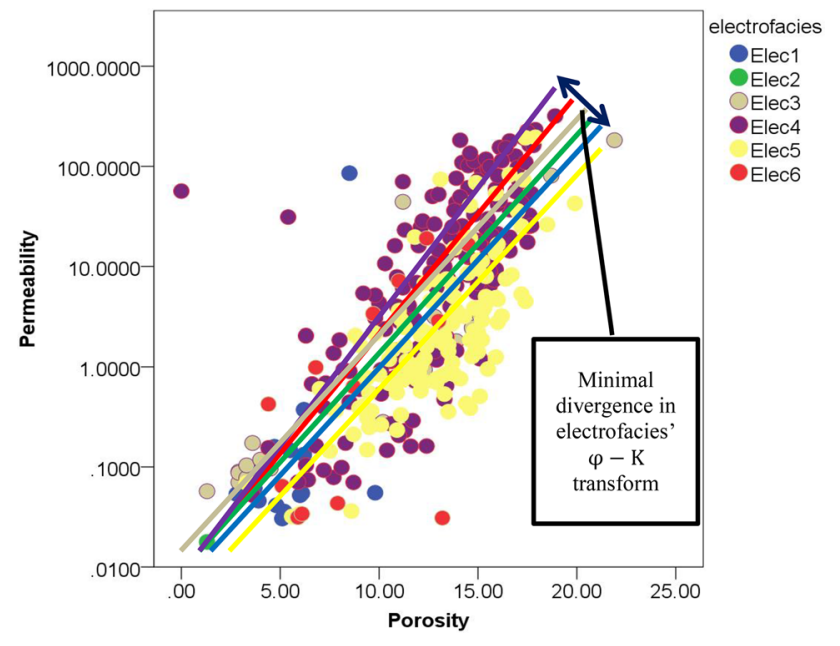

Fig. $7 \varphi-\mathrm{K}$ crossplot in electrofacies the convergence or divergence of the differential between porosity and permeability. If $\varphi-\mathrm{K}$ transforms in electrofacies is nearly overlapping and exhibiting minimal divergence in trend, homogenization by Diagenetic modification (Skalinski and Kenter 2015) may be inferred as a significant contributor to the fluid flow characteristics of the reservoir.

Figure 7 is the $\varphi-\mathrm{K}$ crossplot of the relationship with color representing the different electrofacies. It can be seen that there is a small degree of dispersion in the relationship between different electrofacies proving that the main geologic factor controlling reservoir fluid flow in the Mesozoic strata of Gaoqing area is the transformation of diagenesis (Skalinski and Kenter 2015).

Digenesis mainly consists of compaction, cementation, dissolution and metasomatism. The first three contributes more on the petrophysics of reservoir because metasomatism causes little effect on the petrophysics due to the slight extent of development and the small amount of generation. It can be seen from the micro-observation that the cementation of the reservoir is carbonate cementation. As is shown in Fig. 8, carbonate cementation is colored by red. Quartz grains in gray or white and other quartz grains with asphaltene in black or dark gray and long shape feldspar can also be seen.

Core analysis in carbonate content and permeability makes the crossplot Fig. 9 signifying that the main carbonate content is less $5 \%$ and is not significantly correlated with permeability. The unstable carbonate content of low permeability and ultra-low permeability reservoirs has both low value and high value, and reservoir with carbonate cementation less than 5\% has no significant effect on permeability.

Cementation-intergranular volume projection crossplot can explain the influence of cementation on reservoir petrophysics in this area. Figure 10 shows the effect of compaction and cementation on reservoir-pore volume in previous research results (Wang et al. 2018a). As shown in the figure, the pore space of the reservoir is mostly affected by the compacting effect. A few samples are affected by cementation because of its postion adjacent to unconformity. This is due to the fact that the primary pores near the unconformity
Fig. 8 The carbonate cementation in Well G41
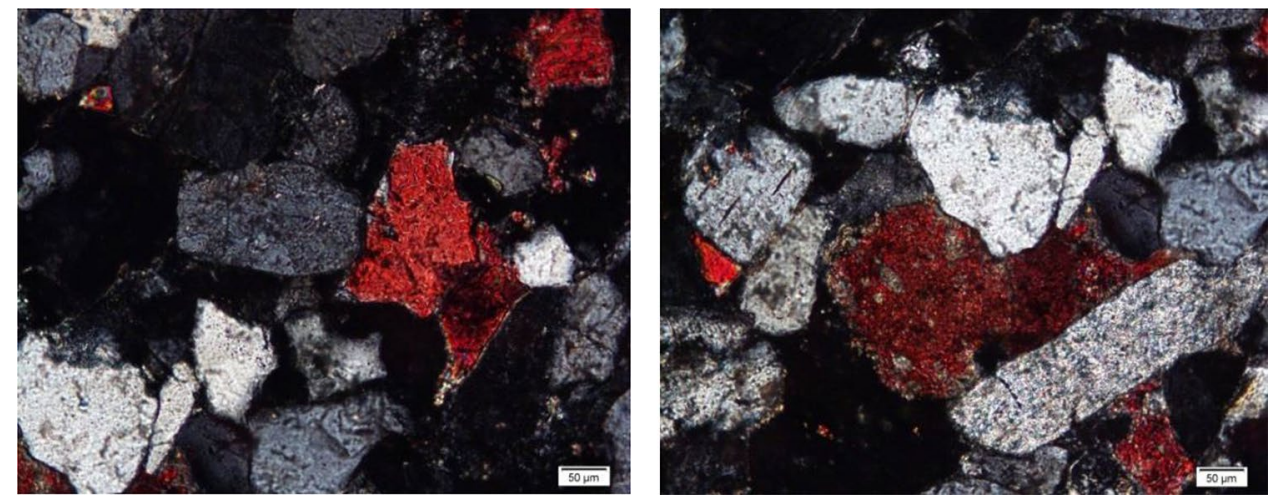


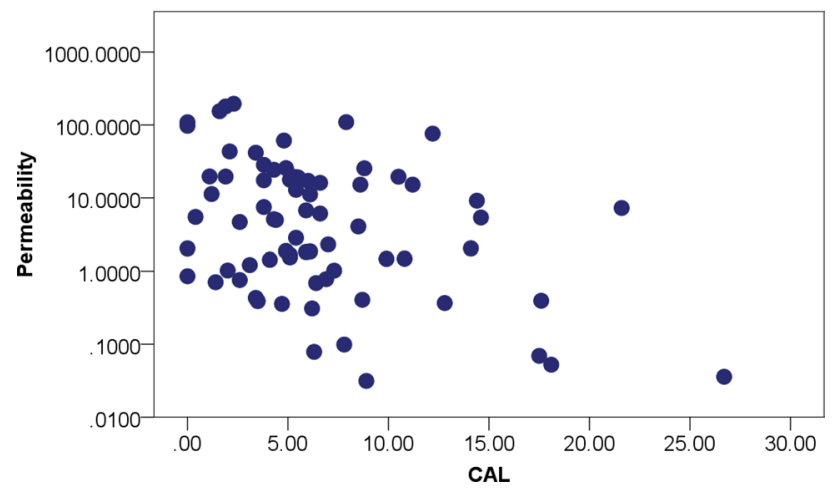

Fig. 9 Carbonate content and permeability crossplot

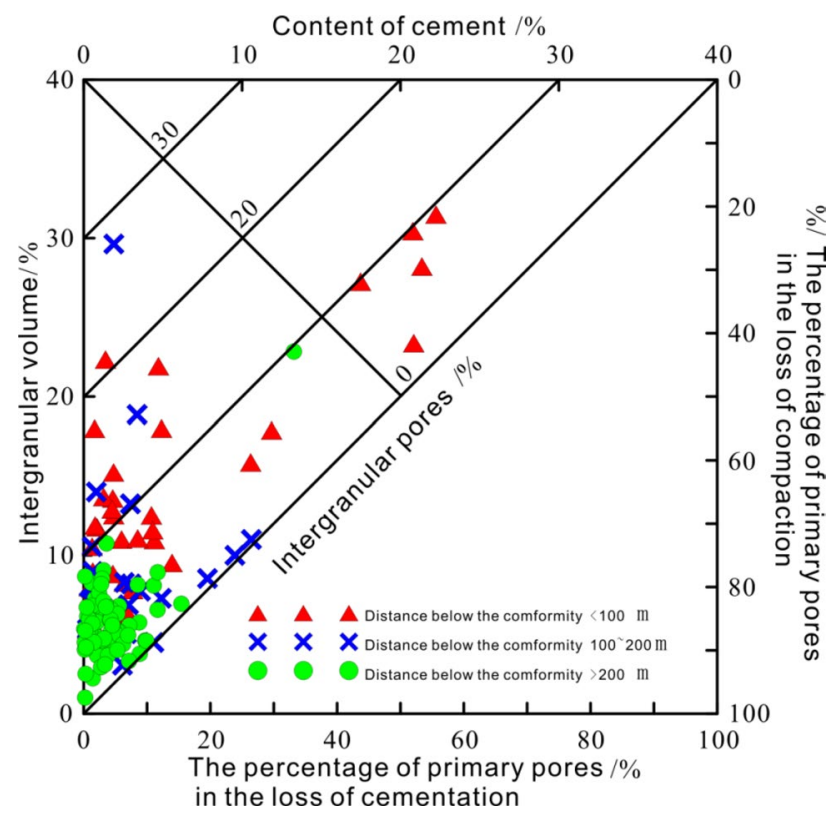

Fig. 10 Cementation-intergranular volume projection crossplot

surface have not been dissolved but carbonate filled in a result of reduction of the pore by cementation obviously. But the main body is far from the unconformity surface, and the compaction effect causes the pore volume to decrease, the throat becomes fine or disappears, supplying no space for the cementation to fill, so the cementation content is low and the cementation effect is weaker. This indirectly indicates that the region's cementation is not strong. Lack of cast core slice in the study makes dissolution hard to evaluate. So the main effect is compaction in a whole view.

The digenesis of this area mainly undergoes compaction, compaction and cementation syngeneic process, and compaction cementation and dissolution syngeneic process (Wang et al. 2018a). Under the precondition of less influence of cementation on reservoir petrophysics, the value of porosity changed by compaction $\Delta \varphi$ is put forward to characterize the reservoir transformation in the diagenetic stage. The initial porosity of the reservoir is $\varphi_{0}$, the current porosity is $\phi$, initial porosity and sorting coefficients $S_{0}$ gains a functional relationship (Pan and Liu 2011), that is

$\varphi_{0}=20.91+22.90 / S_{0}$,

$\Delta \varphi=\varphi_{0}-\varphi$.

The variation of the porosity is related to the sedimentation and diagenesis: the sedimentation mainly affects the initial value of the pore space, and the diagenesis has a more obvious transformation to the pore space. The sorting coefficients are mainly obtained by fitting sorting coefficients of core data in lab. The main component in Elec1, Elec2, and Elec3 is volcanic rock with no concept of sorting coefficients. However, some researchers used the data of mercury injection to study the microstructure of volcanic rocks using the parameter to characterize the arrangement of volcanic particles (Qu et al. 2007). For exploratory research and result comparison, the sorting coefficient of the three electrofacies is set as two based on regional experience (Wang et al. 2018a, b, c). Figure 11 shows the relationship between porosity and permeability, and it is obvious that the permeability becomes smaller as the value of porosity changes.

\section{Factors characterization on permeability modeling controls}

It is known that the change of porosity can better reflect the diagenesis effect on reservoir petrophysics by control factors analysis. The variation of porosity, as the control factor of permeability model, can be used as the characterization parameter of the model. In this study, the stratum has been classified into six kinds of electrofacies. A cluster is regarded as a distinct electroface reflecting formation hydrology, lithology, and diagenetic properties. By petrophysics analysis, a qualitative understanding is obtained by statistical

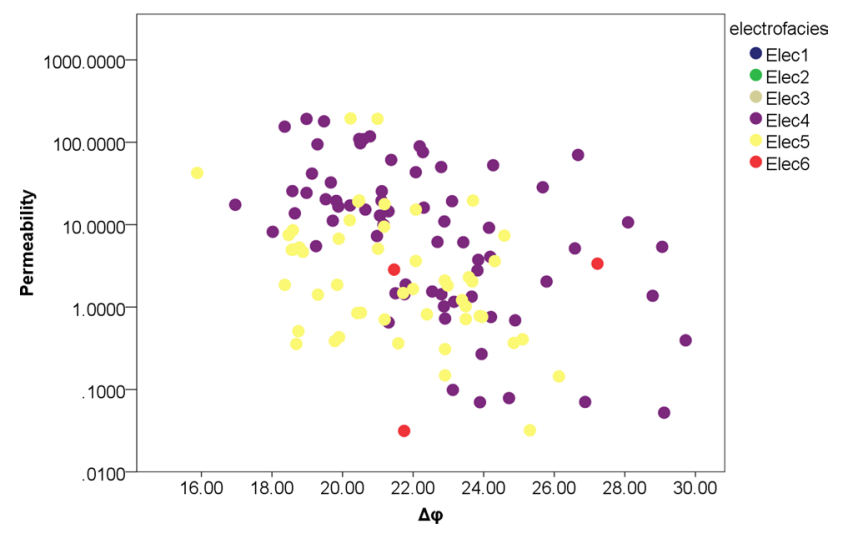

Fig. $11 \Delta \varphi-\mathrm{K}$ crossplot in electrofacies

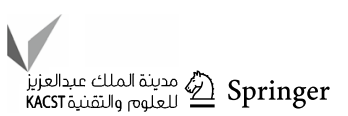


description. It is understood that the electrofacies properties can be used as an important independent variable of permeability modeling on reservoir petrophysics, but there is a certain overlapping zone in pore-permeability distribution. No obvious and concrete boundary can be observed between different electrofacies. The electrofacies classification cannot be used as a single parameter to estimate permeability. SNK(Student-Newman-Keuls) method in multivariate variance analysis is used to verify and evaluate comparisons quantitatively for different electrofacies (Barr et al. 1977). If you draw a statistically significant conclusion, and further infer which groups are different, which groups are not different, or whether all groups are different, SNK method can quantitatively evaluate the difference of permeability between different electrofacies, and explain the relationship between electrofacies and permeability statistically. With Table 3, we can see similar conclusions with the descriptive analysis of petrophysics statistics analysis. $\mathrm{N}$ column represents the sample number and the values in subset are the calculated $P$ values (Demuth 2006) in statistics. $P$ value is the probability that a sample observation or more extreme result will occur when the null hypothesis is true. The dataset are divided into three subsets. Elec1 and Elec2 have similar petrophysics, so do Elec4 and Elec5. Elec3 and Elec6 have obvious overlapping behavior and Elec5 also has a little bit of this behavior. This shows that there are some common petrophysics characteristics in different electrofacies, but the petrophysics have a wide fuzzy area and the electrofacies can be proved to be a very important discrete parameter that can reflect the permeability.

Electrofacies is just an application of the discrete attribute regarded as a distinction that reflects formation features. The well-logging data as continuous data consists of abundant information on hydrology, lithology, and diagenetic properties of the reservoir. DEN and AC logs are indirect measures of porosity. In clastic rocks, they reflect formation permeability. The GR log indicates shale content in sandstone reservoirs, which is inversely related to permeability, particularly in low-permeability layers. The SP log indicates

Table 3 Comparison result of electrofacies in permeability with SNK method

\begin{tabular}{lrccc}
\hline Electrofacies & $N$ & \multicolumn{2}{l}{ Subset } \\
\cline { 3 - 5 } & & 1 & 2 & 3 \\
\hline Elec2 & 2 & -1.1615 & & \\
Elec1 & 17 & -0.9538 & & \\
Elec6 & 13 & -0.2522 & -0.2522 & \\
Elec3 & 22 & -0.1119 & -0.1119 & -0.1119 \\
Elec5 & 127 & & 0.3338 & 0.3338 \\
Elec4 & 174 & & & 0.8405 \\
Sig. & & 0.061 & 0.343 & 0.061 \\
\hline
\end{tabular}

the concentration difference between the mud and the formation water which is affected by hydrology, lithology, and diagenetic characteristics of the reservoir. LLS and LLD logs measure the resistivity in the vicinity of the wellbore and deep into the reservoir, respectively; when these two logs are collectively analyzed, and respecting saturation-height considerations, they give an indication of the invasion severity; hence they are coherently related to permeability.

It is known that there is a certain distribution in different logging properties between electrofacies using a multicrossplot illustrated in Figs. 12, 13, 14, 15, 16, 17 to analyze the relationship between permeability and logging data. (a) Elec1 and Elec4 have a lower GR value. Elec1 displays a relatively compact, ultra-low-permeability distribution, while the Elec 4 has a large distribution range. The distributions of the remaining electrofacies are mainly above 110API and have no obvious distribution characteristics. (b) Elec4 displays a relatively low value distribution in SP, but high value also exists correspondingly. (c) The trend of distribution in LLD and LLS are similar, and Elec4 and Elec5 have significant changes in the resistivity. The rest of the distribution features are not obvious, (d) as for sonic features, Elec1 and

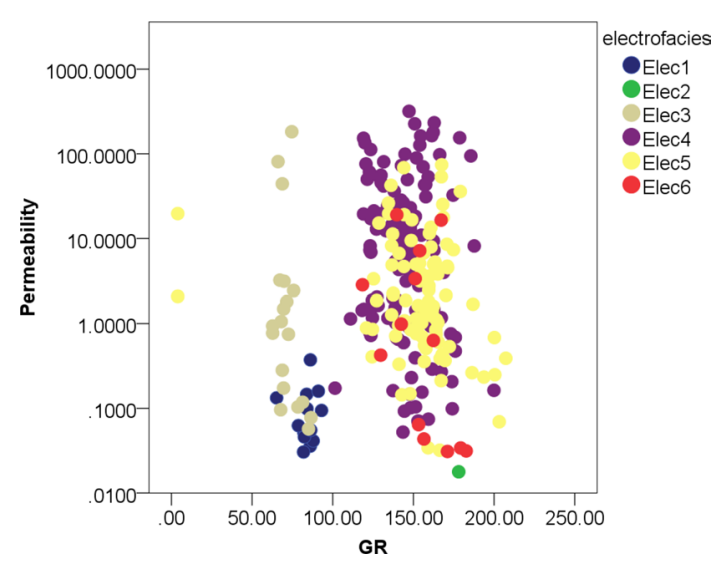

Fig. 12 GR-K crossplot in electrofacies

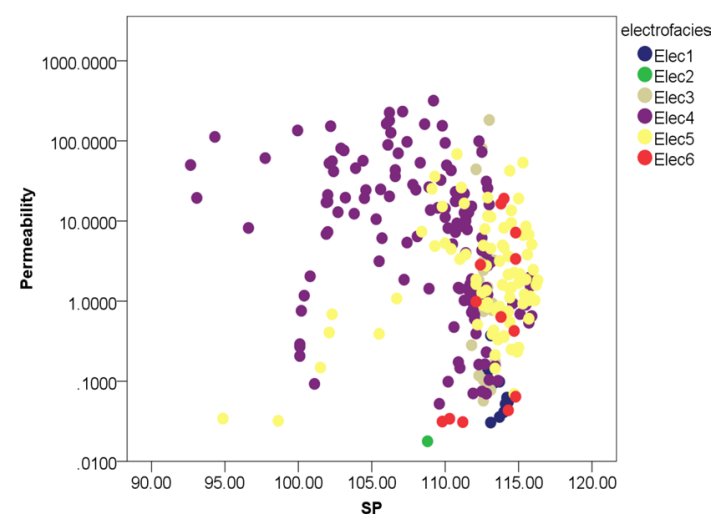

Fig. 13 SP-K crossplot in electrofacies 


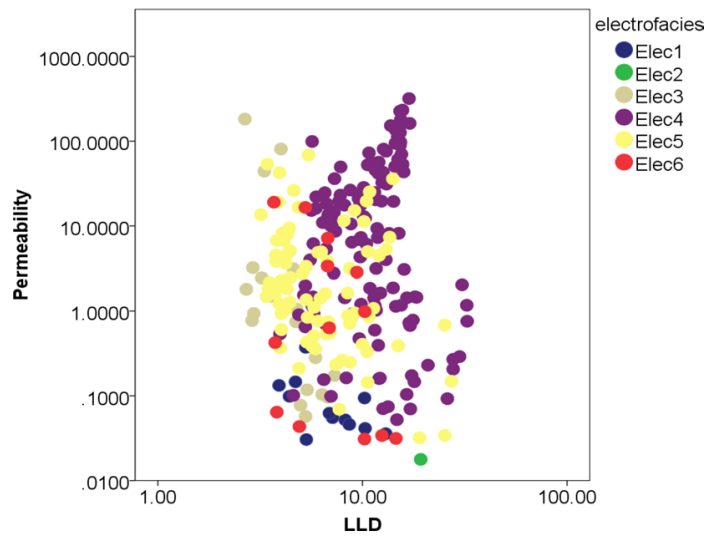

Fig. 14 LLD-K crossplot in electrofacies

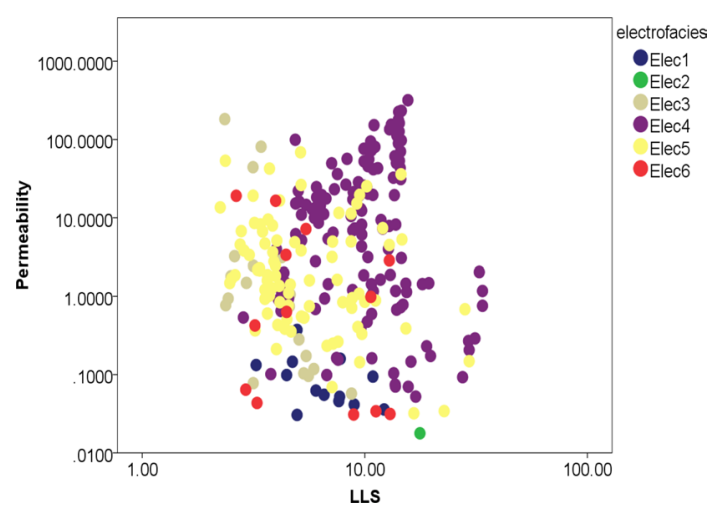

Fig. 15 LLS-K crossplot in electrofacies

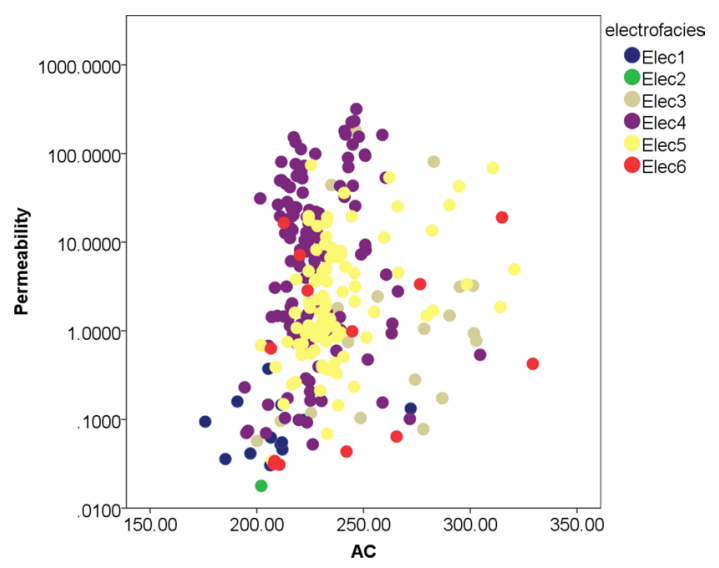

Fig. 16 LLS-K crossplot in electrofacies

Elec4, Elec5 reflects a tendency to increase with the large permeability of acoustic time, and Elec4, Elec5 reflect the tendency of the permeability increase with the same acoustic time overlapping more seriously. (e) The density characteristic is similar to the characteristic distribution of sonic

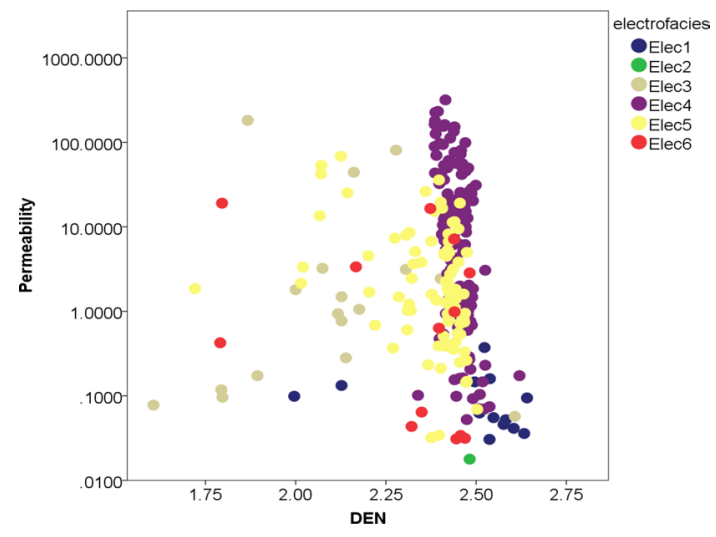

Fig. 17 DEN-K crossplot in electrofacies

features. There are many overlapping areas and no obvious distribution boundaries between different electrofacies.

Using the crossplot to describe the variables, we can get a qualitative understanding of the effect of the different logging data on the permeability model but not a quantitative knowledge of the influence on the primary control and characterize the influence. By the analysis above, variable selection is conducted among the continuous variables, namely $\Delta \varphi$ to represent the strength of the diagenesis; GR to represent the radioactive characteristics of the strata; SP to represent the subsurface fluid percolation characteristic information; LLD and LLS to represent the electrical information of the strata and the flushing zone; $\mathrm{AC}$ to represent the elastic feature of the strata and DEN to represent the density information. Multivariate selection method is using statistics evaluation to carry out forward and backward method (Mark and Goldberg 2001). The result is in Table 4. B is partial regression coefficient and its standard error without normalization. Beta is the normalized regression coefficient. $T$ is the $T$ statistics value to test for the significance of a single coefficient. Sig represents significance to signify statistic difference. The principle of variable selection is to estimate the magnitude that affects the variables through the calculation of statistics of $P$ value which test the possibility that the null hypothesis is true or more serious. The independent variables are sorted based on $P$ value to characterize the respective impact on dependent variable, $K$ (Charniak 1996).

Table 4 shows that the variable $\Delta \varphi$ is firstly included by the forward method. This proves the consistency of statistical model and geological analysis, and also characterizes the availability of the definition of the variable by $\Delta \varphi$. However, beyond our expectation, the SP curve and the LLS curve will be included in the second and third variables in turn, and AC is the fourth variable.

The backward approach first incorporates all variables to calculate the statistics, according to whether it is meaningful in the statistics to delete the variable. The result of backward 
Table 4 The statistic result of forward approach

\begin{tabular}{|c|c|c|c|c|c|c|}
\hline \multicolumn{2}{|c|}{ Model } & \multicolumn{2}{|c|}{ Non-normalized coefficients } & \multirow{2}{*}{$\begin{array}{l}\text { Standard coefficient } \\
\text { Beta }\end{array}$} & \multirow[t]{2}{*}{$T$} & \multirow[t]{2}{*}{ Sig. } \\
\hline & & $B$ & Standard error & & & \\
\hline \multirow[t]{2}{*}{1} & (constant) & 3.330 & 0.693 & & 4.803 & 0.000 \\
\hline & $\Delta \varphi$ & -0.125 & 0.031 & -0.391 & -3.983 & 0.000 \\
\hline \multirow[t]{3}{*}{2} & (constant) & 8.161 & 1.846 & & 4.420 & 0.000 \\
\hline & $\Delta \varphi$ & -0.130 & 0.030 & -0.406 & -4.293 & 0.000 \\
\hline & SP & -0.043 & 0.015 & -0.266 & -2.806 & 0.006 \\
\hline \multirow[t]{4}{*}{3} & (constant) & 11.320 & 2.223 & & 5.092 & 0.000 \\
\hline & $\Delta \varphi$ & -0.111 & 0.030 & -0.346 & -3.631 & 0.000 \\
\hline & SP & -0.072 & 0.019 & -0.444 & -3.760 & 0.000 \\
\hline & LLS & -0.042 & 0.017 & -0.293 & -2.415 & 0.018 \\
\hline \multirow[t]{5}{*}{4} & (constant) & 9.786 & 2.300 & & 4.256 & 0.000 \\
\hline & $\Delta \varphi$ & -0.094 & 0.031 & -0.294 & -3.035 & 0.003 \\
\hline & SP & -0.081 & 0.019 & -0.499 & -4.199 & 0.000 \\
\hline & LLS & -0.040 & 0.017 & -0.280 & -2.348 & 0.021 \\
\hline & $\mathrm{AC}$ & 0.009 & 0.004 & 0.208 & 2.097 & 0.039 \\
\hline
\end{tabular}

approach is the same as the forward method; the reserved variables are $\Delta \varphi, \mathrm{SP}, \mathrm{LLS}$ and AC. The first excluded variable is GR, followed by LLD, DEN. The two methods remain consistent (see Table 5).

Description analysis learned similar distribution trends in LLS to LLD and no obvious characteristic of distribution in SP. But both of them are figured out to indicate permeability included in the modeling by calculation of statistics. Combined with the logging principle, the common denominator in LLS, SP, and AC are all reflective of the flushing zone information. The flushing zone is the part of the borehole near the wellbore which is strongly flushed by the mud filtrate, and the different degrees of mud intrusion will strongly affect the formation conductivity, the electrochemical property and the elastic property in the reservoir with different permeability. It is the most abundant ring zone of permeability information (see Fig. 18).

Analysis of the selection results of independent variables from the logging principle (Schlumberger 1986) presents that: spontaneous potential data, SP is an indicator to a permeable formation by the appearance of the apparent variation in the profile of electrical potential changes of the natural electric field around the borehole. The spontaneous potential is mainly due to the salinity difference of the formation water and the mud to form ion exchange with the formation pressure and the mud column pressure producing potential difference in electrochemical process. The exchange ability of the ion between the formation water and the mud is largely related to the permeability of the strata. Application of LLS in shallow-lateral logging is to measure the resistivity between flushing zone and transition zone, as a result strong permeable formations will invade more mud, and the high resistance of fresh water mud can cause the change of resistance in the flushed zone for the replacement of the low-resistivity formation water in different permeable formations. The statistical conclusion confirms the influence of permeability on the assumption of flushing electrification. In view of the exclusion variable, the first excluded variable GR curve reflects the formation of radioactive, mostly contained by clay volume information, which reveals that it has little impact on permeability. The second exclusion variable LLD and third variables DEN convey more information of uninvaded zone and mud cake, respectively, which is not contributed to manifest information of permeability. Acoustic time logging mainly contains elasticity feature of the flushing zone and zone of transition. As the fourth variable, it reflects a certain degree of reaction to the permeability. However, as a statistics result, little research has been conducted to show it can be inducted by the three logging attribute in theory.

\section{Scale quantification of discrete variable by optimal scale analysis}

The variables characterizing the permeability model are electrofacies, $\Delta \varphi$, SP, LLS, AC based on the analysis above. The types of data attributes are different: electrofacies is a discrete variable, but the others are continuous variables. The scale of the discrete variable is necessary to be quantified for the correct representation of the model and the unification of scales in the other five continuous variables with different attributes should be considered in the modeling process.

The general regression requires data in strict forms as continuous value. When the discrete variable is encountered, the regression cannot accurately reflect the different values of the discrete variables, such as gender variables. It may lose its own significance if discrete variables are 
Table 5 The statistics result of backward approach

\begin{tabular}{|c|c|c|c|c|c|c|}
\hline \multicolumn{2}{|c|}{ Model } & \multicolumn{2}{|c|}{ Non-normalized coefficients } & \multirow{2}{*}{$\begin{array}{l}\text { Standard coefficient } \\
\text { Beta }\end{array}$} & \multirow[t]{2}{*}{$T$} & \multirow[t]{2}{*}{ Sig. } \\
\hline & & $b$ & Standard error & & & \\
\hline \multirow[t]{8}{*}{1} & (constant) & 4.269 & 3.890 & & 1.097 & 0.276 \\
\hline & $\mathrm{AC}$ & 0.015 & 0.006 & 0.337 & 2.571 & 0.012 \\
\hline & DEN & 1.581 & 1.109 & 0.179 & 1.425 & 0.158 \\
\hline & GR & -0.007 & 0.005 & -0.123 & -1.213 & 0.229 \\
\hline & LLD & 0.111 & 0.083 & 0.730 & 1.333 & 0.186 \\
\hline & LLS & -0.141 & 0.075 & -0.988 & -1.880 & 0.064 \\
\hline & SP & -0.071 & 0.022 & -0.438 & -3.176 & 0.002 \\
\hline & $\Delta \varphi$ & -0.090 & 0.031 & -0.281 & -2.914 & 0.005 \\
\hline \multirow[t]{7}{*}{2} & (constant) & 4.559 & 3.894 & & 1.171 & 0.245 \\
\hline & $\mathrm{AC}$ & 0.015 & 0.006 & 0.334 & 2.547 & 0.013 \\
\hline & DEN & 1.627 & 1.112 & 0.185 & 1.463 & 0.147 \\
\hline & LLD & 0.083 & 0.080 & 0.542 & 1.030 & 0.306 \\
\hline & LLS & -0.120 & 0.073 & -0.844 & -1.645 & 0.104 \\
\hline & SP & -0.082 & 0.020 & -0.508 & -4.058 & 0.000 \\
\hline & $\Delta \varphi$ & -0.089 & 0.031 & -0.280 & -2.889 & 0.005 \\
\hline \multirow[t]{6}{*}{3} & (constant) & 5.167 & 3.850 & & 1.342 & 0.183 \\
\hline & $\mathrm{AC}$ & 0.015 & 0.006 & 0.337 & 2.569 & 0.012 \\
\hline & DEN & 1.657 & 1.112 & 0.188 & 1.490 & 0.140 \\
\hline & LLS & -0.047 & 0.018 & -0.331 & -2.684 & 0.009 \\
\hline & SP & -0.088 & 0.020 & -0.541 & -4.459 & 0.000 \\
\hline & $\Delta \varphi$ & -0.089 & 0.031 & -0.278 & -2.867 & 0.005 \\
\hline \multirow[t]{5}{*}{4} & (constant) & 9.786 & 2.300 & & 4.256 & 0.000 \\
\hline & $\mathrm{AC}$ & 0.009 & 0.004 & 0.208 & 2.097 & 0.039 \\
\hline & LLS & -0.040 & 0.017 & -0.280 & -2.348 & 0.021 \\
\hline & $\mathrm{SP}$ & -0.081 & 0.019 & -0.499 & -4.199 & 0.000 \\
\hline & $\Delta \varphi$ & -0.094 & 0.031 & -0.294 & -3.035 & 0.003 \\
\hline
\end{tabular}

labeled directly into the regression model manually label. The optimal scale regression is to solve the problem; it is good at quantifying the discrete variables by different values, and then converts the categorical variables to the numerical model for statistical analysis (Paolillo 2009). It can be said that with the optimal scale method, it will greatly improve the processing ability of categorical variable data and break the restriction of discrete variables to the analysis model selection, and enlarge the application ability of regression analysis. Using the optimal scale analysis, the variables required for modeling the permeability are analyzed as follows:

As shown in Fig. 19, the optimal scale transformation takes a linear transformation to the continuous variable with $\mathrm{x}$ axis representing its original value and $\mathrm{y}$ axis representing the converted value after scale quantification. It does not affect the control of the independent variable for the continuous variable like well data and $\Delta \varphi$. For the discrete variable, electrofacies, the optimal scale analysis is quantified. The quantified electrofacies and the petrophysics analysis as mentioned before are in accordance reflecting impact on the permeability of the scale represented in the model established by the value. The specific electrofacies values are as shown in Table 6.

\section{Model establishment by fuzzy logic}

Fuzzy Logic theory is a logic extension which allows the existence of partial truth between the entirely true and entirely false and take all options between these alternatives into account (Zadeh 1965). Fuzzy logic is an effective tool for modeling uncertainty, which is associated with vague, imprecise, and/or lack of information about a particular factor in a problem (Boske and Diem 2000; Lababidi and Baker 2003). The Permeability estimation problem is typical situation of imprecise data involving uncertainty, fuzzy correlation between rock properties, and the effects of manmade and/or natural disturbances. For this type of issue, fuzzy logic can tolerate and interpret subjective concepts uniformly such as very high permeability or very low permeability, which effectively fills the missing information gap making the problem to be mathematically expressed and calculated instead of ignoring or minimizing it (Cuddy 1997) which will result in an inherent error term. In addition, the

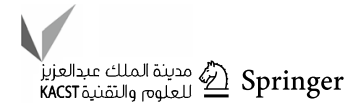



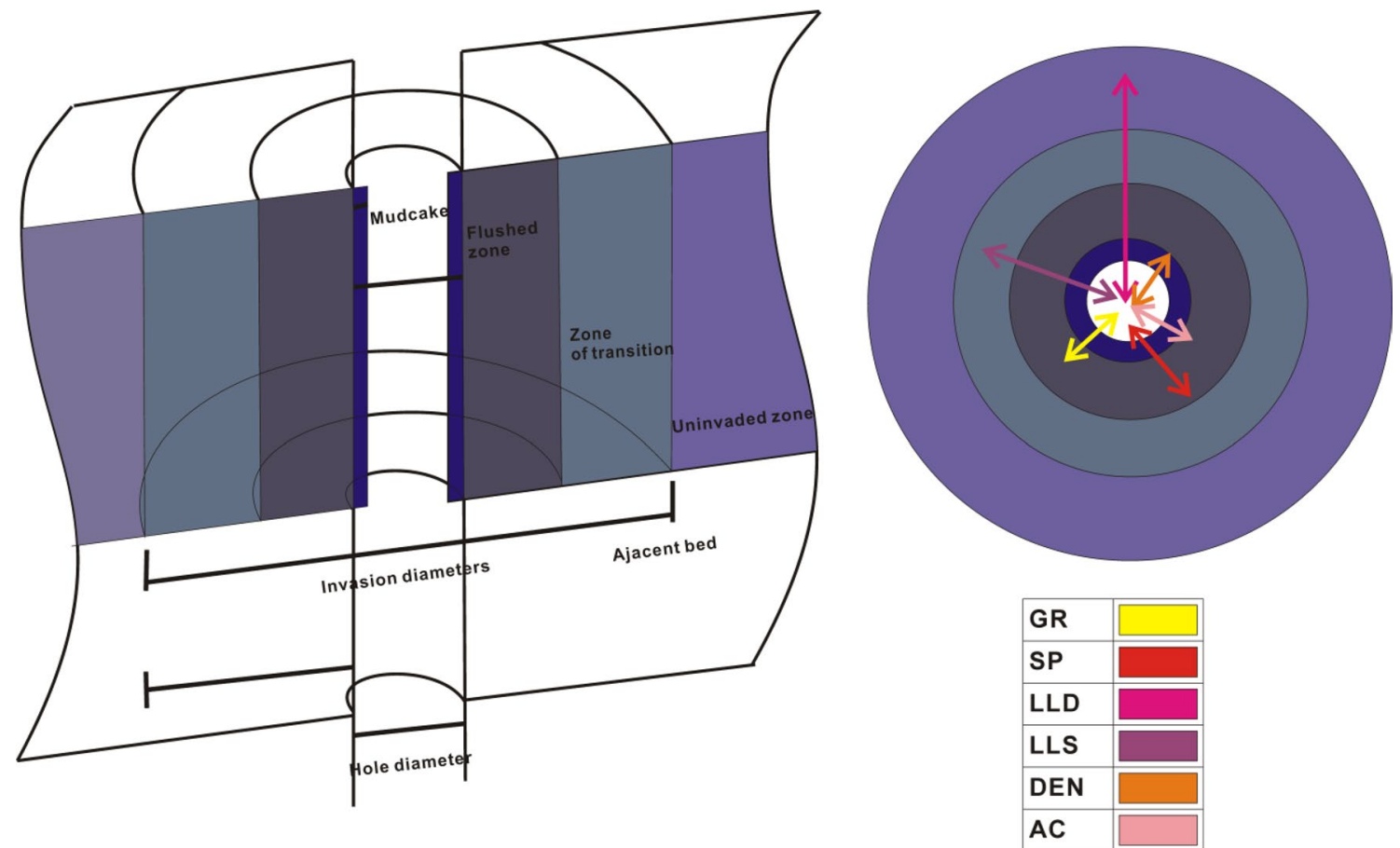

Fig. 18 Diagram of the intrusion characteristics of the reservoir and corresponding radial detection range

fuzzy logic model is completely open and easy to understand and requires minimal user intervention. Not only the interpretation of fuzzy logic results is simple, but also they often describe complex nonlinear systems that violate conventional logic (Nashawi and Malallah 2009).

The user chooses the number of bins into which the training data is to be divided. The program sorts the training data into roughly equal-sampled bins, starting at the lowest values and extending to the highest. For each data bin the program calculates the mean $(\mu)$ and the standard deviation $(\sigma)$ for all the associated curves to be used in the prediction. The mean and standard deviation values are then used by the program, when run in prediction mode, to find the most likely result.

To make the prediction, the program first calculates the fuzzy probability that an input log is in a certain bin. The following equation is used for this:

$P\left(C_{b}\right)=\sqrt{n_{b}} \times e^{-(C-\mu)^{2} /\left(2 \times \sigma_{b}^{2}\right)}$,

where $P\left(C_{b}\right)$ the probability that curve $C$ is in bin $b, n_{b}$ the number of samples in bin $b, C$ the input value for curve $C$, $\mu_{b}$ the mean value for curve $C$ for bin $b, \sigma_{b}$ b the standard deviation for curve $C$ for bin $b$.

The probabilities for all the input curves are then combined as follows:

$\frac{1}{P_{b}}=\frac{1}{P\left(C 1_{\mathrm{b}}\right)}+\frac{1}{P\left(C 2_{\mathrm{b}}\right)}+\frac{1}{P\left(C 3_{\mathrm{b}}\right)}+\ldots \ldots$ where $P_{b}$ the total probability for bin $b, P\left(C 1_{\mathrm{b}}\right)$ the probability for curve $C 1$ for bin $b$.

The most likely solution will be the bin with the highest probability. The program outputs the most likely bin result, the second highest probability bin, and a weighted average of these two highest results. The weighting is done as follows:

$R_{\mathrm{av}}=\frac{R_{\mathrm{ml}} \times P_{\mathrm{ml}}+R_{\mathrm{sl}} \times P_{\mathrm{sl}}}{P_{\mathrm{ml}}+P_{\mathrm{sl}}}$,

where $R_{\mathrm{av}}$ average weighted result, $R_{\mathrm{ml}}$ most likely result, $R_{\mathrm{sl}}$ second most likely result, $P_{\mathrm{ml}}$ probability of most likely result, $P_{\text {sl }}$ probability of the second most likely result.

To give a quantitative feel for the errors in the results, high and low result curves can be generated for the most likely and the weighted average results. These curves are constructed as follows: at each level the bin probabilities are converted to a normalized (0-1) cumulative frequency distribution. The Result Bin Percentile is found (ResPC).

The Low result is the bin that has the percentile ResPc-Er. The High result is the bin that has the percentile ResPc $+\mathrm{Er}$ where Er is the percentile error set with a value of $25 \%$ by the manual. 


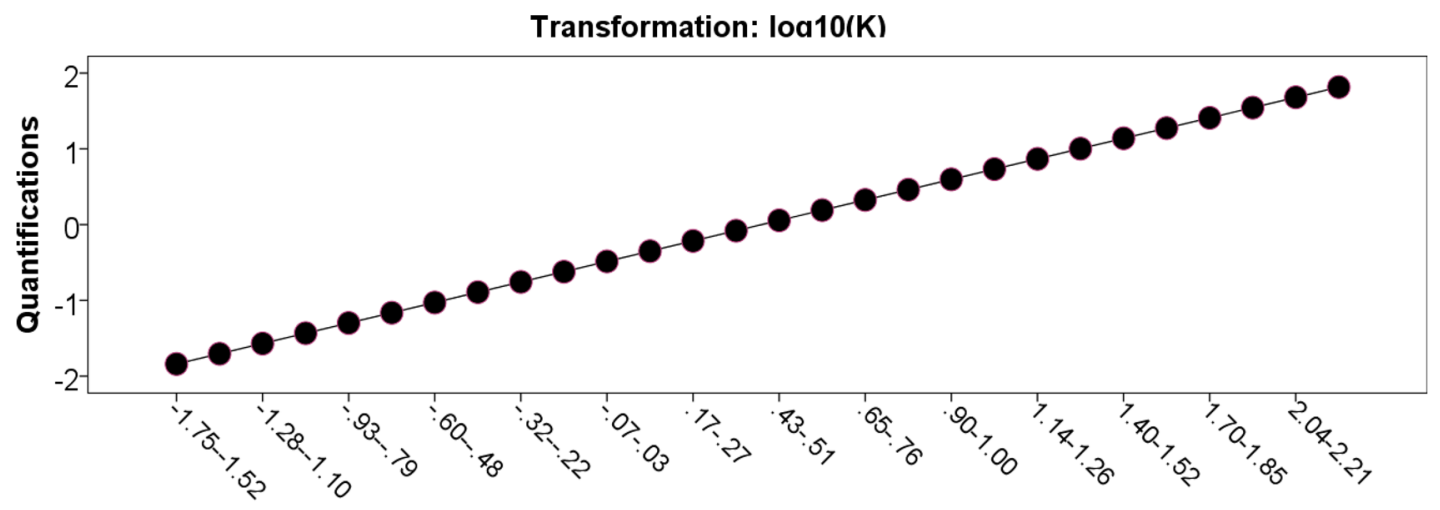

\section{Categories}
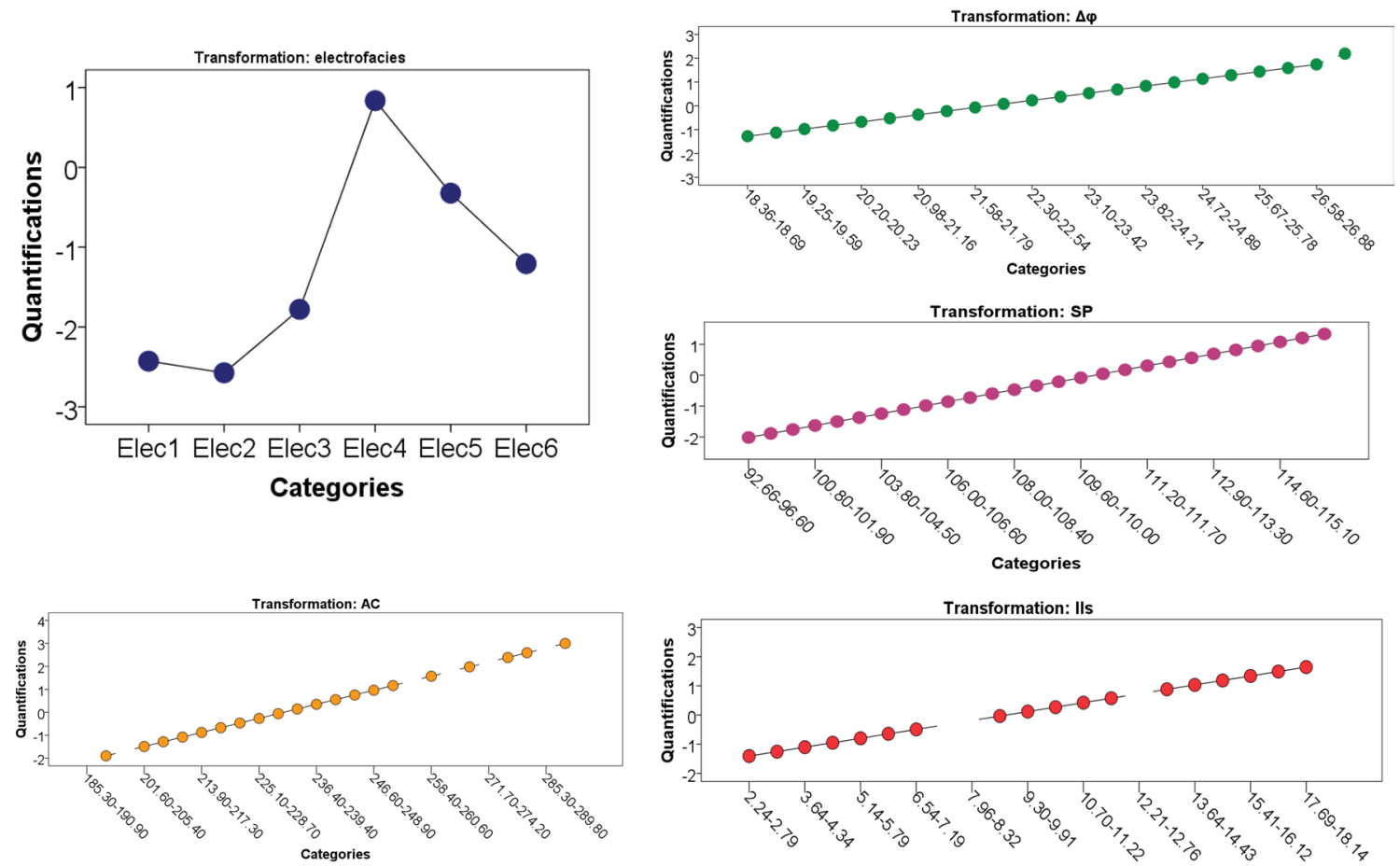

Categories

Fig. 19 Variables transformation by optimal scale analysis

Table 6 The transformation value of electrofacies

\begin{tabular}{ll}
\hline Category & Quantification \\
\hline Elec1 & -2.428 \\
Elec2 & -2.574 \\
Elec3 & -1.779 \\
Elec4 & 0.835 \\
Elec5 & -0.323 \\
Elec6 & -1.206 \\
\hline
\end{tabular}

\section{Results and discussion}

The well plot is shown with the results of the estimated permeability in Fig. 20: the first to fifth track is the independent variable applied for the modeling of permeability, and the sixth path is average weighted result, most likely result and compared to cores plugs. The seventh track is the most likely result, and the range between the low result and the high result. The ninth track is the spectrum of the probability obtained at each sampling point. It is known from the plot that the calculated permeability is in good accordance with the trend of core permeability.

There are several understandings on the comparison of calculated permeability and core permeability in the whole 


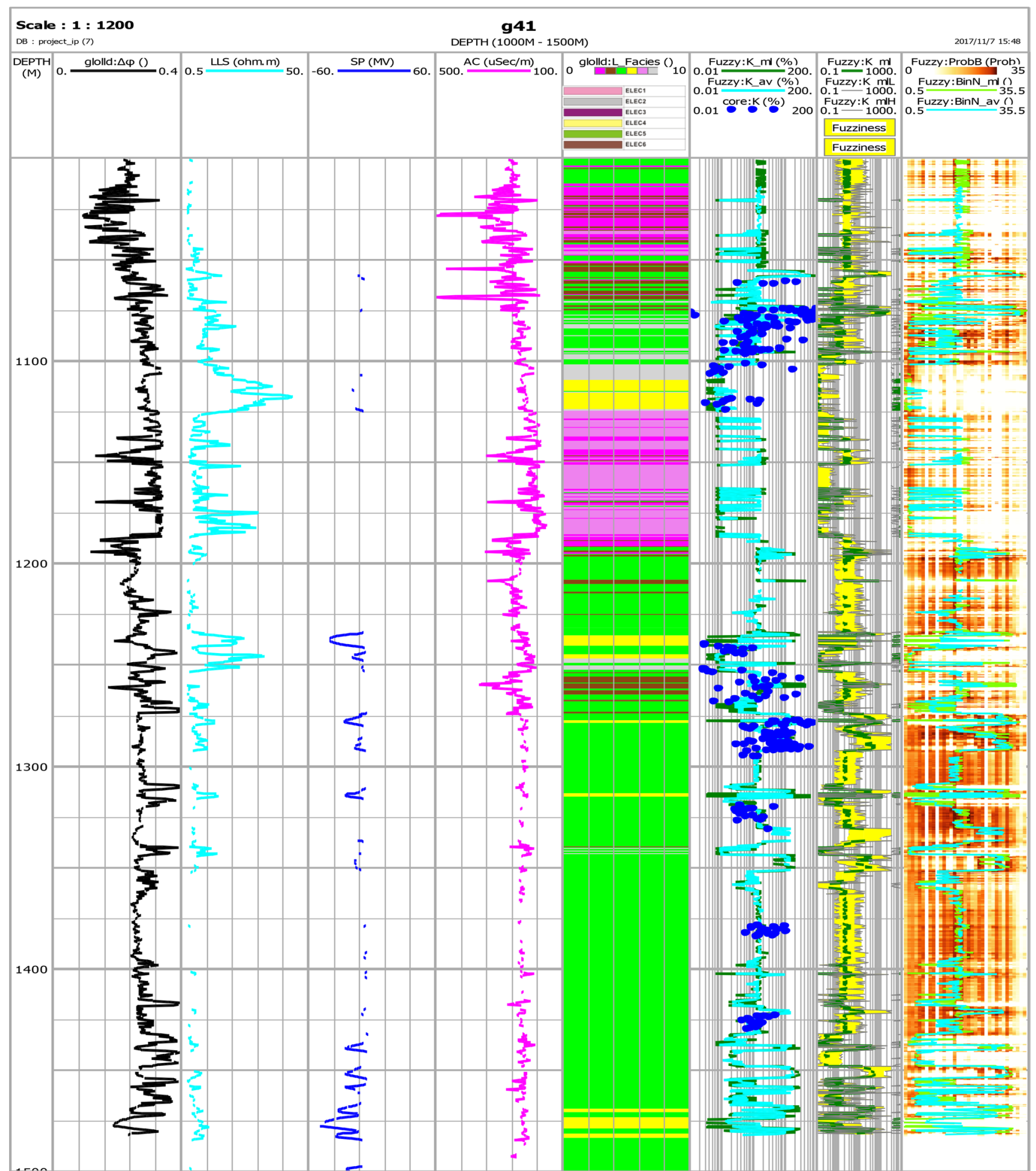

Fig. 20 The well plot of Well G41

well-plot view: There are two periods of volcanic intrusions with the volcanic rocks in the upper part which are affected by dissolution due to close to the unconformity surface with a mean value nearly $2 \times 10^{-3}$, while the lower part retains the dense characteristics of volcanic rocks, the permeability is only $0.0765 \times 10^{-3} \mu \mathrm{m}^{2}$. In $1070-1100 \mathrm{~m}$ interval, electrofacies change more frequently. The core permeability is $173 \times 10^{-3} \mu \mathrm{m}^{2}$ and the calculation permeability is $163 \times 10^{-3} \mu \mathrm{m}^{2}$ with the relative error only $6 \%$ in the middle- and low-permeability area at $1075 \mathrm{~m}$; 
The interval adjacent below results in a sharp change in permeability due to the existence of Elec2, which is wellreflected in the core data.

Scaling up the plot in Fig. 21, the estimation of permeability is better reflected in the permeability of the changes in the track; precise estimation of Elec2 in the interval in $1100 \mathrm{~m}$ is consistent with the core permeability indicating that the calculated permeability is of availability for the low-permeability range; The interval in $1120 \mathrm{~m}$ is characterized by the edges of a thick layer of Elec 4 and at the junction of Elec3. The core permeability shows that there is a thin low-permeability zone between the ultra-low permeability reservoirs, which calculates the permeability of $0.284 \times 10^{-3} \mu \mathrm{m}^{2}$ but core permeability of $2.5 \times 10^{-3} \mu \mathrm{m}^{2}$ presenting a slight error in the accuracy comparison of cores, which shows that the algorithm is still unable to break the limit of the resolution of the well-logging. It also exists in the interval of $1089 \mathrm{~m}$ and $1103 \mathrm{~m}$.

The accuracy rate of permeability calculation in the interval of $1230 \mathrm{~m}$ and $1275-1300 \mathrm{~m}$ is the highest with the core permeability (see Fig. 22). The main reason is that petrophysics characteristics in the overlying strata are significant with a larger thickness and between clear boundaries of electrofacies; the calculated permeability retains the lowest degree of accuracy with core permeability in the interval of $1250-1270 \mathrm{~m}$ with the petrophysics of the layer in middle permeability, low permeability and ultra-low permeability at the same time. More types, thin thickness and rapid changes in electrofacies and the complicated petrophysics characteristics of Elec6 as the main component in the interval leads the logging response to be greatly affected by the adjacent layer with unmatched penetration information of the corresponding layer that cannot be correctly indicated.

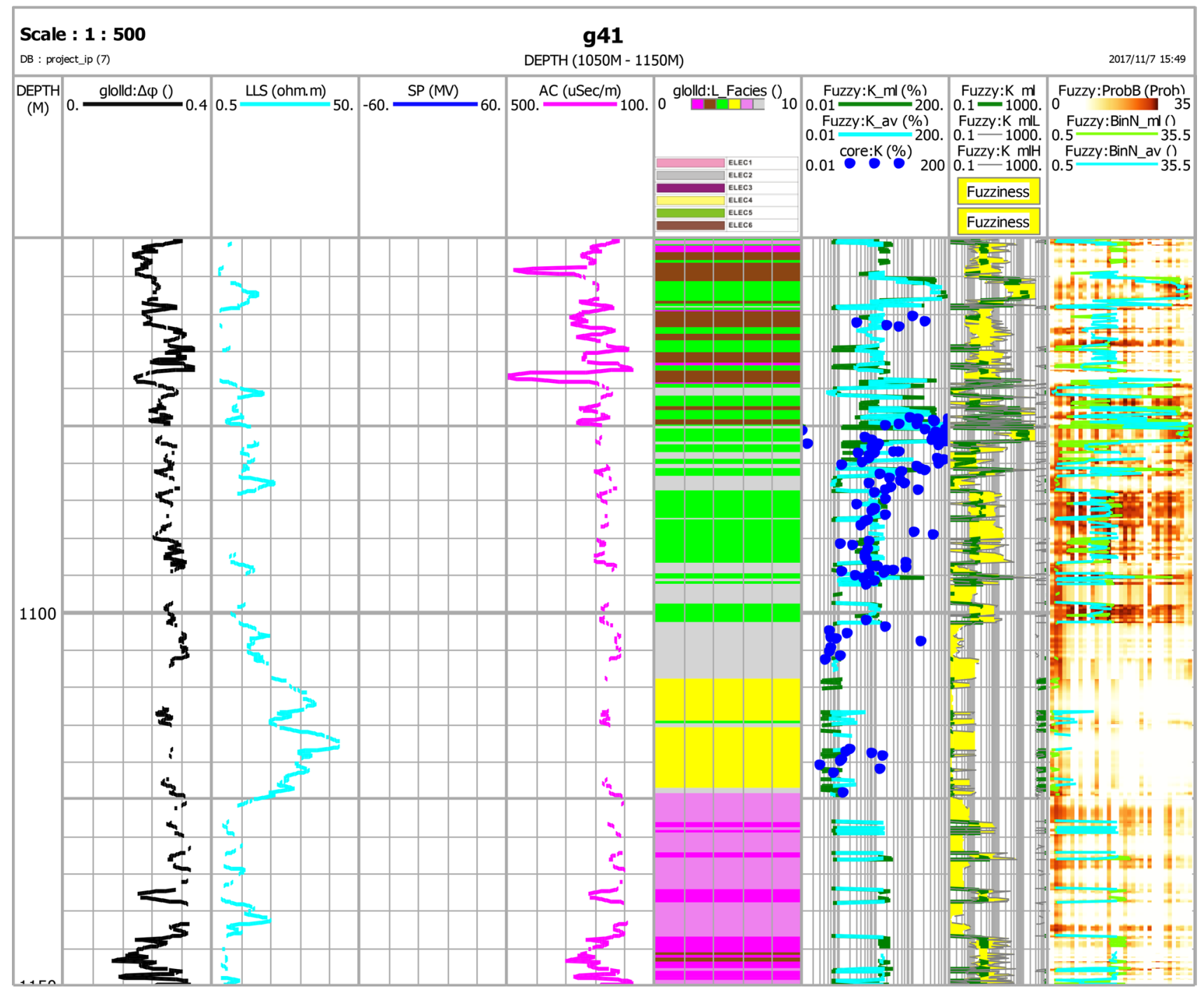

Fig. 21 The well plot of Well G41 between 1000 and $1150 \mathrm{~m}$ 


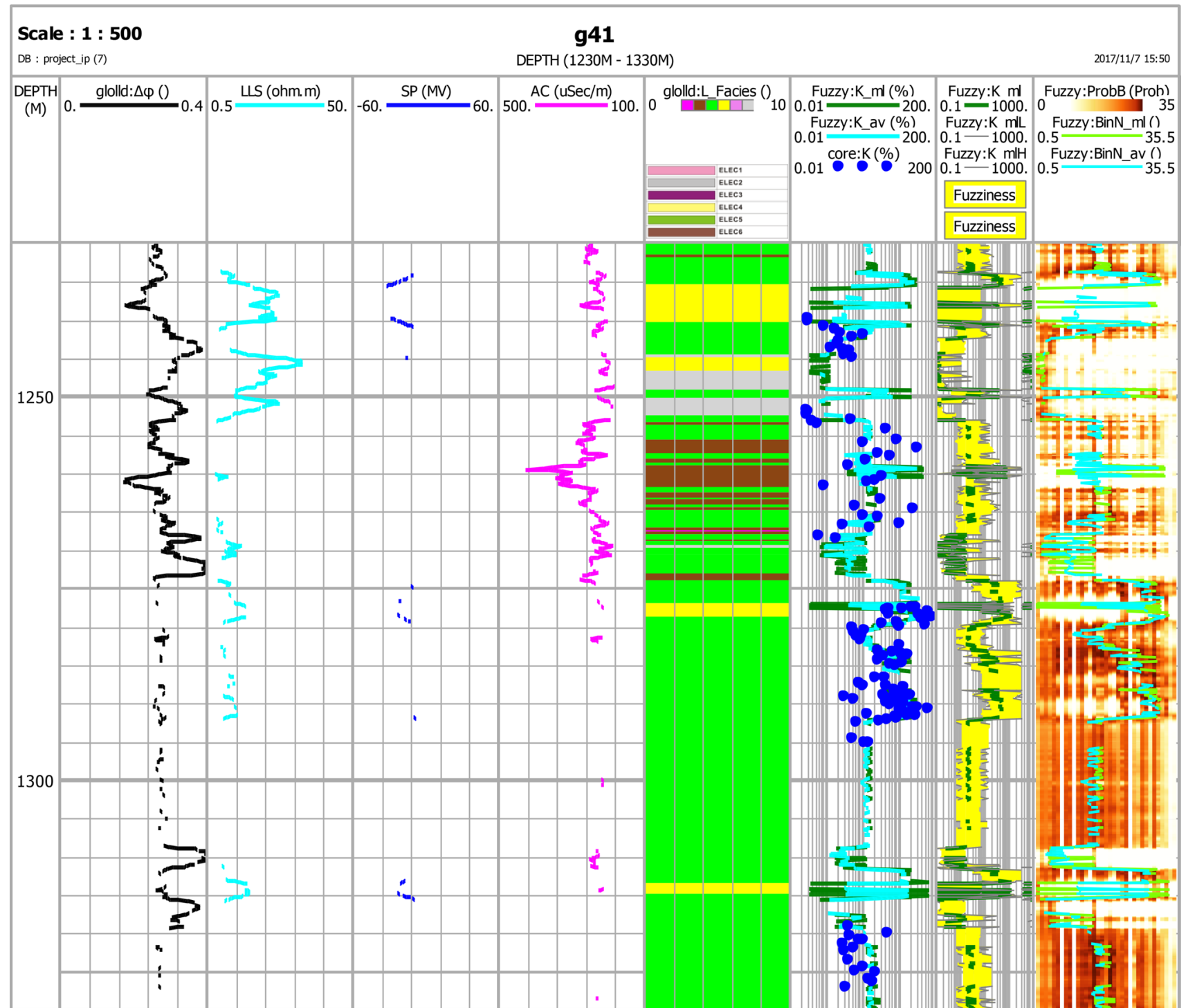

Fig. 22 The well plot of Well G41 between 1230 and $1330 \mathrm{~m}$

A comprehensive knowledge about the precision of the model can be obtained by the analysis above: In the view of electrofacies, the result of permeability calculation is good in Elec4 and Elec5, and the error exists relatively more in Elec2 and Elec6. This is the reason as petrophysics in Elec4 and Elec5 are obvious, but Elec2 and Elec6 are more complex. In terms of thickness, the effect on the medium-thick layer is good, but for the turbulent sedimentary environment with more types of electrofacies and rapid changes with thin thickness, permeability prediction effect is not good. In the perspective of permeability distribution, the model has the ability to adapt to the full range of permeability, which can not only identify low permeability, ultra-low permeability reservoir, but also can identify middle-high permeable layer and have good patience. At the same time, the method has a clue on uncertainty analysis because it determines the upper and lower limit of permeability calculation.

Figures 23, 24, 25 are the comparison crossplots of the calculated permeability (logarithm) and core permeability (logarithm) with the calculation of correlation coefficient. In the analysis of the calculation result by optimized approach in Fig. 23, the calculated permeability characteristics of different electrofacies are consistent with the petrophysics analysis above: Elec1 and Elec2 mainly develops the ultra-low permeability strata in a value below $1 \times 10^{-3} \mu^{2}$; the main part of Elec4 is higher than Elec5; Elec6 has a good calculation accuracy with a few dispersed points; core permeability range of Elec 3 is large, and the calculation of permeability is mainly between 1 and $10 \times 10^{-3} \mu \mathrm{m}^{2}$. In the comparison with multiple linear regressions with the same parameter 


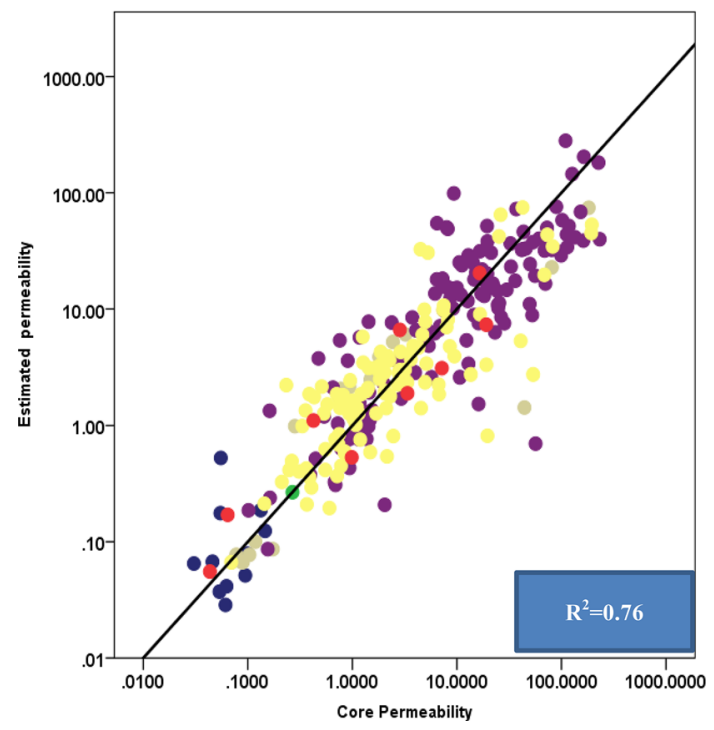

Fig. 23 Cross plot of results from estimated permeability versus core permeability with feature engineering

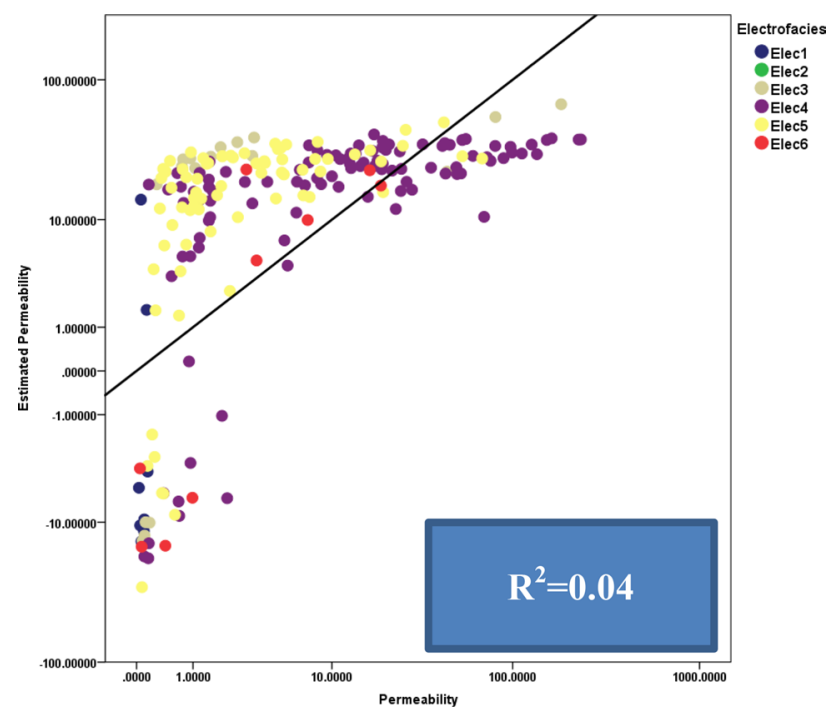

Fig. 24 Cross plot of results from estimated permeability by linear regression model versus core permeability

in Fig. 24 and the fuzzy model without feature engineering containing all parameters collected in Fig. 25, the accuracy increased significantly. In the multiple linear-regression model, the accuracy is bad with a narrow distribution above the value of 10 . Moreover, it calculates negative in ultralow permeability area. The regression model apparently acts badly in estimation with the correlation coefficient of 0.07. Compared with model without feature engineering, the result maintains a good trend with the core, but estimated less observation by the reference line. It means that the fuzzy logic is well-behaved in estimation in permeability but the

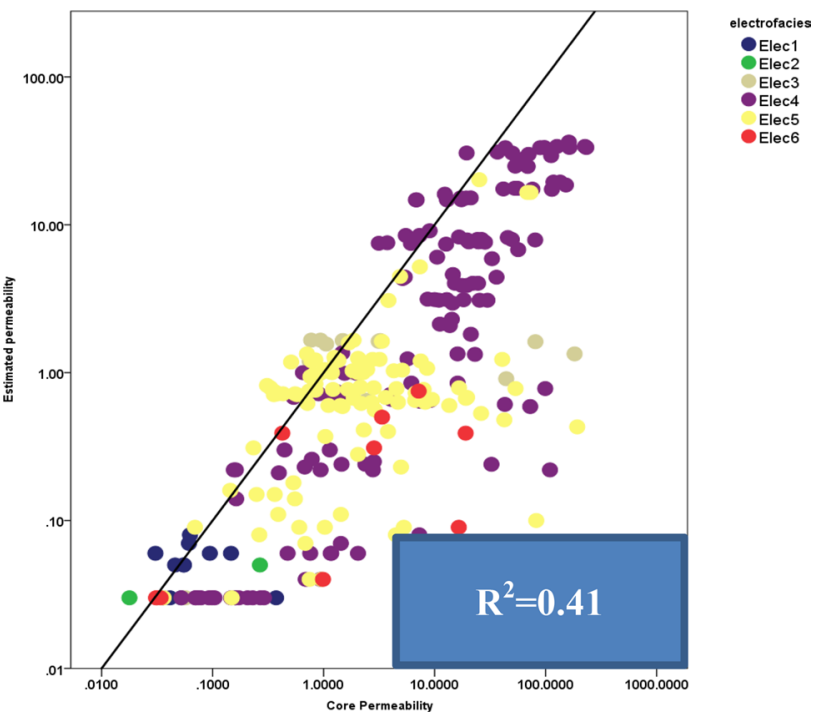

Fig. 25 Cross plot of results from estimated permeability by fuzzy logic without feature engineering versus core permeability

correlated parameter should be purified to feature the relationship. In the result with optimized method, the core points of these samples are estimated well and the correlation coefficients are calculated to reach the 0.76 , which fully meets the needs of exploration production.

\section{Conclusion}

The fuzzy logic application based on permeability control factors of low permeability and low-permeability reservoirs is proposed and the formation permeability of Mesozoic strata in Gaoqing area is estimated and the following conclusions are obtained.

1. The Mesozoic strata in the Gaoqing area are characterized by low permeability, and ultra-low permeability. Based on the optimized $\mathrm{K}$ nearest to the neighbor clustering,the reservoir is classified into six electrofacies in which Elec1 and Elec2 show significant ultra-low porosity and ultra-low permeability features; petrophysics of Elec 4 and Elec5 is relatively better and Elec3 and Elec6 are the most complicated. Each electrofacies has its own characteristic distribution while different electrofacies have a large range of overlapping of the range that cannot be directly classified by the electrofacies prediction.

2. According to logging data analysis, the main factors affecting reservoir permeability are the homogenization effect caused by diagenesis. The cementation effect is not strong in the area. The petrophysics are mainly related to the effect of compaction and dissolution, and

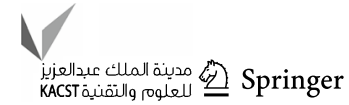


the change of pore value caused by diagenesis is used to characterize the transformation effect of diagenesis.

3. Variable selections in the permeability modeling is conducted by the forward and backward approach integrating the result of electrofacies, SP, LLS, AC and $\Delta \varphi$ as a combination of independent variables. Combined with the result of variable selection and the logging principle, this paper comprehensively explains the meaning of each independent variable achieving the unification of the mathematical model and the method principle.

4. Apply the optimal scale analysis to scaling the measurement of the model in discrete variable and the continuous variable, and get the value of the discrete variable in electrofacies and the scale conversion value of each continuous variable.

5. Fuzzy logic is assembled to model permeability with the filtered independent variable. By the accuracy analysis, the correlation coefficients reached 0.76 with the elimination of data points in scale error. The application is practical for the ultra-low permeability-to-middle permeability stratum, and the calculation precision is high. As for the stratum of the thin layer or in frequent sedimentary changes, the adaptability is poor.

Acknowledgements This research work was jointly funded by the National Science and Technology Major Project of China (Grant No. 2017ZX05009001) and the Innovation Research Program for College Graduates (Grant No. YCX2018006). Thanks are also due to Oil and Gas Exploration Management Center of SINOPEC Shengli Oilfield for data preparation and permission to publish this paper.

Open Access This article is distributed under the terms of the Creative Commons Attribution 4.0 International License (http://creativeco mmons.org/licenses/by/4.0/), which permits unrestricted use, distribution, and reproduction in any medium, provided you give appropriate credit to the original author(s) and the source, provide a link to the Creative Commons license, and indicate if changes were made.

\section{References}

Abbaszadeh M, Fujii H, Fujimoto F (1996) Permeability prediction by hydraulic flow units-theory and applications. SPE Form Eval 11(4):263-271

Amabeoku MO, Funk JJ, Al-Dossary SM, Al-Ali HA (2001) Calibration of permeability derived from NMR logs in carbonate reservoirs. SPE middle east oil show, 17-20 March, Manama, Bahrain. Society of Petroleum Engineers

Anifowose FA, Labadin J, Abdulraheem A (2013a) A least squaredriven functional networks type-2 fuzzy logic hybrid model for efficient petroleum reservoir properties prediction. Neural Comput Appl 23(Supplementary 1):179-190

Anifowose FA, Labadin J, Abdulraheem A (2013b) Prediction of petroleum reservoir properties using different versions of adaptive neuro-fuzzy inference system hybrid models. Int J Comput Inf Syst Ind Manag Appl 5:413-426
Anifowose F, Labadin J, Abdulraheem A (2014a) Improving the prediction of petroleum reservoir characterization with a stacked generalization ensemble model of support vector machines. Appl Soft Comput 26:483-496. https://doi.org/10.1016/j.asoc.2014.10.017

Anifowose F, Labadin J, Abdulraheem A (2014b) Non-linear feature selection-based hybrid computational intelligence models for improved natural gas reservoir characterization. J Nat Gas Sci Eng 21:397-401

Anifowose F, Adeniye S, Abdulraheem A (2014c) Recent advances in the application of computational intelligence techniques in oil and gas reservoir characterization: a comparative study. J Exp Theor Artif Intell 26(4):551-570

Barr DL, Mutschler FE, Lavin OP (1977) Keybam — a system of interactive computer programs for use with the petros petrochemical data bank. Comput Geosci 3(3):489-496

Boske C, Diem S (2000) How to improve reservoir characterization using intelligent systems: a case study: Toldado field in Colombia. Oil Field 14(2012):21-41

Baziar S, Tadayoni M, Nabi-Bidhendi M, Khalili M (2014) Prediction of permeability in a tight gas reservoir by using three soft computing approaches: a comparative study. J Nat Gas Sci Eng $21: 718-724$

Carman PC (1937) Fluid flow through granular beds. Trans Am Inst Chem Eng 15:150-166

Charniak E (1996) Statistical language learning. MIT Press, Cambridge

Civan F (2002) Relating permeability to pore connectivity using a power-law flow unit equation. Petrophysics 43(6):457-476

Coates GR, Dumanoir JL (1974) A new approach to improved logderived permeability. Log Anal 15(1):17-31

Coates GR, Miller M, Gillen M, Henderson C (1991) The mril in conoco 33-1 an investigation of a new magnetic resonance imaging log. Spwla annual logging symposium

Cuddy S (1997) The application of mathematics of fuzzy logic to petrophysics. In: SPWLA 38th annual logging symposium, 15-18 June, Houston, Texas. Society of Petrophysicists \& Well Log Analysts

Demuth J (2006) Basic statistics and pharmaceutical statistical applications. Francis \& Taylor, Routledge

Geerits TW, Altunbay M, Tang XM (1999) Comparision Between stoneley, NMR, and core derived permeabilities. In: SPWLA 40th Annual Logging Symposium

Gholami R, Shahraki AR, Paghaleh MJ (2012) Prediction of hydrocarbon reservoirs permeability using support vector machine. Math Probl Eng 2012(1024-123X):139

Hassan A, Nooruddin F, Anifowose, Abdulraheem A (2013) Applying artificial intelligence techniques to develop permeability predictive models using mercury injection capillary-pressure data. In: Presented at the SPE Saudi Arabia Section Annual Technical Symposium and Exhibition, Dhahran, Saudi Arabia

Jiang Y (1998) The type and distribution characteristics of in Gaoqing field. J Univ Pet 22(4):5, 33-37

Kozeny J (1927) Uber die kapillare leitung des wassers im boden, Royal Academy of Science, Vienna. Proc Class I 136:271-306

Lababidi HMS, Baker CGJ (2003) Web-based expert system for food dryer selection. Comput Chem Eng 27(7):997-1009

Mark J, Goldberg MA (2001) Multiple regression analysis and mass assessment: a review of the issues. Appraisal J 56(1):89-109

Nashawi IS, Malallah A (2009) Improved electrofacies characterization and permeability predictions in sandstone reservoirs using a data mining and expert system approach. Petrophysics 50(3):250-268

Pan GF, Liu Z (2011) The quantitative simulation method of sandstone porosity evolution - an case in Yanchang group of Zhenjing area, Ordos basin. Acta Petrol Sin 32(2):249-256

Paolillo J (2009) Chap. 4 log-linear modelling and logistic regression

Qian X, Zuo K, Jie B (2016) New laplacian-based feature selection method. computer engineering and applications. Comput Eng Appl 
Qu YM, Shu P, Ji XY (2007) Study on the microstructure of volcanic rock reservoir in Qingshen gas field of Songliao basin. J Jilin Univ (Earth Sci Edn) 37(4):721-725

Quintero L, Boyd A, Gyllensten, El-Wazeer F (1999) Comparision of permeability from NMR and production analysis in carbonate reservoirs, SPE56798: society of petroleum engineers, presented at the annual technical conference and exhibition, Texas

Schlumberger (1986) Advanced interpretation of wire line logs

Sen PN, Straley C, Kenyon WE, Whittingham MS (1990) Surface-tovolume ratio, charge density, nuclear magnetic relaxation, and permeability in clay-bearing sandstones: Sen, P.N; Straley, C; Kenyon, W.E; Whittingham,M.S Geophysicsv55, n1, jan 1990, p61-69. Int J Rock Mech Min Sci Geomech Abstracts 27(4):199

Skalinski M, Kenter JAM (2015) Carbonate petrophysical rock typing: integrating geological attributes and petrophysical properties while linking with dynamic behaviour. Geol Soc London Spec Publ 406(1):229-259

Vernik L (2000) Permeability prediction in poorly consolidated siliciclastics based on porosity and clay volume logs. Log Analyst 41(2):138-147

Wang Y, Yang S, Lu Y (2018a) Evaluation method of low permeability reservoirs based on logging petrophysical facies identification: a case study of the upper member of Mengyin formation in
Gaoqing area, Dongying depression. J China Univ Min Technol 47(6):1388-1399

Wang X, Yang S, Zhao Y, Wang Y (2018b) Lithology identification using an optimized knn clustering method based on entropyweighed cosine distance in mesozoic strata of gaoqing field, Jiyang depression. J Pet Sci Eng 166:157-174

Wang X, Yang S, Zhao Y, Wang Y (2018c) Improved pore structure prediction based on MICP with a data mining and machine learning system approach in mesozoic strata of gaoqing field, jiyang depression. J Pet Sci Eng 171C:362-339

Winkler KW (1989) Permeability and borehole stoneley waves: comparison between experiment and theory. Geophysics 54(54):66

Zadeh LA (1965) Fuzzy sets, information and control. Inf Control $8(3): 338-353$

Zeng L, Li XY (2009) Fractures in sandstone reservoirs with ultra-low permeability: a case study of the upper triassic yanchang formation in the ordos basin, china. AAPG Bull 93(4):461-477

Publisher's note Springer Nature remains neutral with regard to jurisdictional claims in published maps and institutional affiliations.

\title{
Affiliations
}

\author{
Xidong Wang ${ }^{1,2} \cdot$ Shaochun Yang ${ }^{1,2} \cdot$ Ya Wang $^{1,2} \cdot$ Yongfu Zhao ${ }^{1,2,3} \cdot$ Baoquan Ma ${ }^{1,2}$ \\ 1 School of Geosciences, China University of Petroleum (East \\ China), Qingdao 266580, China \\ Oil and Gas Exploration Management Center of SINOPEC \\ Shengli Oilfield Company, Dongying 257000, China
}

2 Laboratory for Marine Mineral Resources, Qingdao

National Laboratory for Marine Science and Technology,

Qingdao 266071, China 